\title{
A comprehensive review on hybrid electric vehicles: architectures and components
}

\author{
Krishna Veer Singh $^{1} \cdot$ Hari Om Bansal ${ }^{1} \cdot$ Dheerendra Singh $^{1}$
}

Received: 23 February 2018/Revised: 31 January 2019/Accepted: 18 February 2019/Published online: 8 March 2019

(C) The Author(s) 2019

\begin{abstract}
The rapid consumption of fossil fuel and increased environmental damage caused by it have given a strong impetus to the growth and development of fuelefficient vehicles. Hybrid electric vehicles (HEVs) have evolved from their inchoate state and are proving to be a promising solution to the serious existential problem posed to the planet earth. Not only do HEVs provide better fuel economy and lower emissions satisfying environmental legislations, but also they dampen the effect of rising fuel prices on consumers. HEVs combine the drive powers of an internal combustion engine and an electrical machine. The main components of HEVs are energy storage system, motor, bidirectional converter and maximum power point trackers (MPPT, in case of solar-powered HEVs). The performance of HEVs greatly depends on these components and its architecture. This paper presents an extensive review on essential components used in HEVs such as their architectures with advantages and disadvantages, choice of bidirectional converter to obtain high efficiency, combining ultracapacitor with battery to extend the battery life, traction motors' role and their suitability for a particular application. Inclusion of photovoltaic cell in HEVs is a fairly new concept and has been discussed in detail. Various MPPT techniques used for solar-driven HEVs are also discussed in this paper with their suitability.
\end{abstract}

Hari Om Bansal

hbansal@pilani.bits-pilani.ac.in

1 Power Electronics and Drives Laboratory, Department of Electrical and Electronics Engineering, Birla Institute of Technology and Science, Pilani, Rajasthan, India
Keywords Hybrid electric vehicle · Hybrid energy storage system · Architecture - Traction motors - Bidirectional converter

\begin{tabular}{ll} 
Abbreviations & and symbols \\
ABS & Antilock braking system \\
AC & Alternating current \\
ADTR & Antidirectional-twin-rotary \\
ADVISOR & Advanced vehicle simulator \\
ANN & Artificial neural network \\
ASCI & Auto-sequential commutated mode single- \\
& phase inverter \\
BEV & Battery electric vehicle \\
BLDC & Brushless DC motor \\
CD & Charge depletion \\
CDFIM & Cascaded DFIM \\
CF-qZSI & Current-fed quasi-ZSI \\
CMPPT & Centralized MPPT \\
CS & Charge sustaining \\
CSI & Current source inverter \\
CS-PMSM & Compound-structure PMSM \\
CVT & Continuous variable transmission \\
DC & Direct current \\
DFIM & Doubly fed induction motor \\
DMPPT & Distributed MPPT \\
DRM & Double-rotor machines \\
DTC & Direct torque control \\
e-CVT & Electronic continuous variable \\
& transmission \\
EM & Electric motor \\
EMS & Energy management system \\
EREV & Extended range electric vehicle \\
ESS & Energy storage system \\
EV & Electric vehicle \\
FC & Fuel cell \\
\hline
\end{tabular}




\begin{tabular}{|c|c|}
\hline FCEV & Fuel cell electric vehicle \\
\hline FEM & Finite element method \\
\hline FL & Fuzzy logic \\
\hline FOC & Field-oriented control \\
\hline FLC & Fuzzy logic controller \\
\hline GA & Genetic algorithm \\
\hline HESS & Hybrid energy storage system \\
\hline HEV & Hybrid electric vehicle \\
\hline IC & Incremental conductance \\
\hline ICE & Internal combustion engine \\
\hline ICV & Internal combustion vehicle \\
\hline IGBT & Insulated gate bipolar transistor \\
\hline $\mathrm{IM}$ & Induction motors \\
\hline IMCCR & Induction motor with compound cage rotor \\
\hline IPMSM & $\begin{array}{l}\text { Interior permanent magnet synchronous } \\
\text { motor }\end{array}$ \\
\hline$I_{\mathrm{sc}}$ & Incremental short-circuit current \\
\hline KKT & Karush-Kuhn-Tucker \\
\hline $\mathrm{LC}$ & Inductor capacitor \\
\hline MFM-BDRM & $\begin{array}{l}\text { Magnetic field-modulated brushless } \\
\text { double-rotor machine }\end{array}$ \\
\hline MOSFET & $\begin{array}{l}\text { Metal-oxide-semiconductor field-effect } \\
\text { transistor }\end{array}$ \\
\hline MPC & Model predictive controller \\
\hline MPP & Maximum power point \\
\hline MPPT & Maximum power point tracker \\
\hline MRAC & Model reference adaptive controller \\
\hline M-SRM & Modular-switched reluctance motor \\
\hline NPC & Neutral point clamped \\
\hline $\mathrm{P} \& \mathrm{O}$ & Perturb and observe \\
\hline PAM & Pulse amplitude modulation \\
\hline PHEV & Plug-in HEV \\
\hline PI & Proportional integral \\
\hline PM & Permanent magnet \\
\hline PMBLDC & Permanent magnet BLDC \\
\hline PMSM & Permanent magnet synchronous motor \\
\hline PSO & Particle swarm optimization \\
\hline PV & Photovoltaic \\
\hline PVHEV & Solar-driven HEV \\
\hline PWM & Pulse width modulation \\
\hline $\mathrm{RC}$ & Resistance capacitor \\
\hline SA & Simulated annealing \\
\hline SBP & Synergetic battery pack \\
\hline SFO & Stator flux oriented \\
\hline SOC & State of charge \\
\hline SRM & Switched reluctance motor \\
\hline STA & Supertwisting algorithm \\
\hline TTR & Through-the-road \\
\hline TCO & Total costs of ownership \\
\hline $\mathrm{UC}$ & Ultracapacitor \\
\hline
\end{tabular}

VF-ZSI Variable frequency impedance source inverter

$\begin{array}{ll}V_{\mathrm{oc}} & \text { Open-circuit voltage } \\ \text { V2G } & \text { Vehicle to grid } \\ \text { VSI } & \text { Voltage source inverter } \\ \text { ZSI } & \text { Impedance (Z) source inverter } \\ \text { XHEVs } & \text { Full HEVs and PHEVs }\end{array}$

\section{Introduction}

A well-knit and coordinated transportation provides mobility to people and goods. The transportation sector mainly consists of road, railway, ships and aviation, where road transportation consumes $75 \%$ of the total energy spent on transportation. The automobile industry plays a significant role in economic growth of the world and hence affects the entire population. Since vehicles mostly run on internal combustion engine (ICE), the transportation industry is accountable for $25 \%-30 \%$ of the total greenhouse gases emission [1]. ICE works in the process of fuel combustion resulting in the production of various gases like $\mathrm{CO}_{2}, \mathrm{NO}_{2}, \mathrm{NO}$ and $\mathrm{CO}$ [2] which cause environmental degradation in the form of greenhouse effect and are responsible for their adverse effect on human health. To overcome this, the transportation industry is trying hard to manufacture vehicles that can run on alternate power sources. Electric vehicles (EVs) were tried as a solution in 1881 where battery alone propelled the vehicle and therefore required a bulky battery pack. Absence of an ICE handicapped these vehicles with a short driving range [3]. Hybrid electric vehicles (HEVs) were conceptualized to bridge the power of ICE and the emission-free nature of EVs. HEVs offer better fuel efficiency over ICE-based vehicles and generally work in charge-sustaining (CS) mode where the state of charge (SOC) of battery is maintained throughout the trip. The issue with CS mode is that its charging efficiency relies mainly on regenerative braking and gasoline, so plug-in HEVs (PHEVs) were conceptualized as a possible solution. Unlike HEVs, PHEVs have the additional facility to be charged externally through power outlets. Most of the power in a PHEV is derived from an electric motor (EM) which acts as a primary source, while ICE acts as a backup. As the battery SOC reaches a particular threshold, the PHEV behaves like a regular HEV, and the ICE kicks in and acts as a primary power source. The PHEVs mainly work in charge depletion (CD) mode where SOC is depleted up to a threshold level. PHEVs extend the all-electric range, improve local air quality and also may have grid connection capability.

Another possible approach for extending the electric range of an HEV is to allow continuous charging of the battery while running. The emergence of solar-driven 
HEVs (PVHEVs) leads to continuous charging of batteries by means of solar energy, which minimizes the usage of gasoline and hence reduces environmental pollution.

Robust and affordable batteries are a primary challenge for hybrid vehicles. Various HEV battery compositions have been tried in the past with the best results from lithium-ion derivatives. Three levels of integration of battery packs are possible in vehicles: (1) singular battery cells, (2) modules, comprised of individual battery cell, and (3) battery packs, comprised of modules. Battery should be able to supply high power over short periods and must be capable of enduring millions of transient shallow cycles over vehicle life. To extend the range and life of a battery, it can be interfaced with an ultracapacitor (UC) which permits longer life cycle, higher rate of charge/discharge and lower internal resistance which result in lesser heat loss and better reliability. UC improves the efficiency cycle to around 90\% from $80 \%$ [4]. The combination of battery and UC forming a hybrid energy storage system (HESS) is more efficient as compared to their individual performances.

The fundamental requirement for traction motors used in HEVs is to generate propulsion torque over a wide speed range. Two most commonly used motors in HEV propulsion are permanent magnet motor (PM) and induction motor (IM). There are various hybrid cars now available and manufactured by Audi, BMW, Chevrolet, Ford, Honda, Mercedes, McLaren, Nissan, Mitsubishi, Hyundai, Porsche, Tesla, Toyota, etc. The fuel consumption saving by a few models is shown in Table 1 [5].

Various possible architectures of an HEV are presented in Sect. 2, and bidirectional converters reported in the literature are discussed in Sect. 3. The HESS is given in Sect. 4, and Sect. 5 details the various motors used in HEVs and their controlling strategies. Section 6 deals with various MPPT algorithms used in PVHEVs, Sect. 7 points out the flipside of hybrid vehicles, and Sect. 8 presents the conclusion and recommendation. The methodology adopted for constructing this review paper is shown in the form of a flowchart in Fig. 1.

\section{Architecture of HEV}

The key components in an HEV consist of an electric motor (EM), battery, convertor, ICE, fuel tank and control board. These components can be categorized into three groups:

1. Drivetrains-physically integrate the ICE power source and electric drive.

2. Battery/energy storage system (ESS)—emphasizes large or modest energy storage and power capabilities.
3. Control system-instructs electric systems/ICE and manages the HESS.

These components can be integrated in different ways and sizes which results in variation in vehicle design. Based on the component integration, drivetrains mainly include series, parallel and power split designs. In [6] the HEV's architecture has been classified into six different categories, which are mild/microparallel, parallel, series, power split, combined and through-the-road (TTR) hybrids.

In series $\mathrm{HEV}$, the power sources provide electrical energy at DC bus, which is then converted to traction power [7]. In parallel HEVs, traction power can be supplied by ICE or EM alone, or together by both the sources. The EM is used to charge the HESS by means of regenerative braking [8]. The parallel mild HEV is an ideal option as they provide a prime trade-off between the cost of vehicle and its performance [9]. Complex HEVs incorporate features of both parallel as well as series architecture. They are almost like the series-parallel hybrid except for the variance in power flow of the motor, which is bidirectional in complex hybrid and unidirectional in seriesparallel HEVs. The disadvantage of complex hybrid is its complexity in design. A pictorial representation of these architectures is given in Fig. 2.

Architecturally, PHEV is similar to HEVs except for a large-size onboard battery, having high energy density and efficiency. The combination of $\mathrm{CS}$ and $\mathrm{CD}$ modes requires a more complex control strategy than in an HEV. PHEVs begin operation in $\mathrm{CD}$ mode; and as soon as the battery reaches a threshold value of SOC, the battery shifts to CS mode until the vehicle is parked and recharged. The architecture of a solar-driven HEV (PVHEV) is similar to the PHEV except for an additional photovoltaic (PV) panel, which charges the battery during a sunny day. To extract the maximum power from PV panels, the maximum power point tracker (MPPT) algorithms are applied. The block diagram of PVHEV is shown in Fig. 3.

Patterns of power flow:

The power flows in HEVs to encounter the load demand are given in Fig. 4. There are many possible patterns as given below [10]:

1. powertrain 1 alone delivers power to load;

2. powertrain 2 alone delivers power to the load;

3. both powertrains 1 and 2 deliver power to load at the same time;

4. powertrain 2 obtains power from load (regenerative braking);

5. powertrain 2 obtains power from powertrain 1 ;

6. powertrain 2 obtains power from powertrain 1 and load at the same time;

7. powertrain 1 delivers power to load and to powertrain 2 at the same time; 


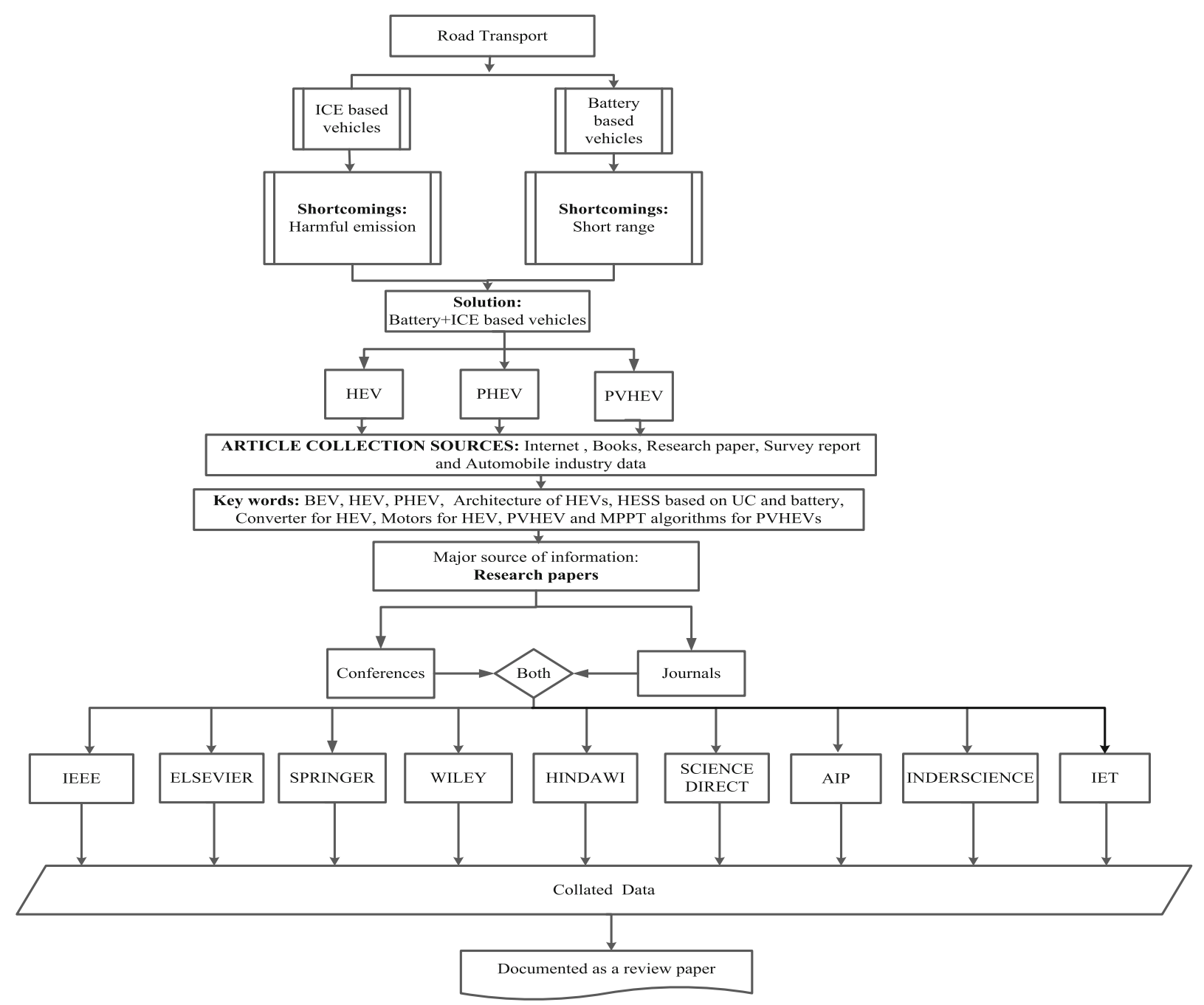

Fig. 1 Methodology adopted for constructing this review paper

8. powertrain 1 delivers power to powertrain 2 , and powertrain 2 delivers power to load;

9. powertrain 1 delivers power to load, and load delivers power to powertrain 2 .

Various papers have been published by researchers on the architecture of hybrid vehicles, and some of them are discussed here. In [11] a small ICE/generator was added to the battery-powered EV to develop a series hybrid drivetrain. The series hybrid drivetrain has some prominent benefits: (1) the ICE and the driven wheels are not coupled mechanically, which compels ICE to operate at its narrow optimal region; (2) single-torque source operation simplifies the speed control; (3) the torque-speed characteristic of EM obviates multigear transmission; and (4) easy drivetrain control, simple structure and easy packaging. However, it suffers from some drawbacks, as follows: (1) the conversion of energy takes place in two steps, i.e., mechanical to electrical through generator and vice versa through motor, and hence results in more energy losses; (2) two electric machines are required, i.e., generator and motor separately; and (3) a big size traction motor is required. The series hybrid drivetrain is mostly used in heavy vehicles such as buses, trucks and military vehicles. This configuration was also considered for the analysis of hybrid lithium high-energy battery [12]. In [13], the PHEV is simulated for series and parallel architectures and it is concluded that during powering mode, the operating points of the motor for parallel PHEV are more concentrated in the extended high-speed, high-efficient region. In case of parallel PHEV, regenerative braking takes place in a high efficiency region which is not the case in the series counterpart. While analyzing the effect of different functions on energy management strategies apropos of both architectures, the parallel configuration was found to be superior [14]. 
In $[15,16]$, power split was considered for the analysis of the through-the-road (TTR) architecture, a subcategory of parallel architecture. In [17], the split-parallel architecture for TTR and its control challenges are detailed. Miller [18] employed power split architecture as it provides better liberty of power control. He also showed that electronic continuous variable transmission (e-CVT) was more efficient than the mechanical continuous variable transmission (CVT). In [7], it is discussed that hybrid cars use parallel and power split architecture, but heavy hybrid vehicles use the series architecture, so small ICE is required. Series, parallel and power split architectures have been presented in [19]. In [20], the power split architecture and its modeling in a systematic way are detailed. In [21], an energy management system (EMS) for power split/parallel architecture of HEV was employed to improve the battery life and powertrain energy efficiency. The results showed that the proposed two propulsion machines improved the powertrain efficiency by 5\% as compared to one propulsion machine. In [22], a parallel active topology was used with a fuzzy logic controller (FLC) which has been implemented for online energy management of an EV. In [23], a similar kind of strategy fused with particle swarm optimization (PSO) and simulated annealing (SA) is proposed to minimize the fuel consumption and emissions for a parallel HEV. In [24], the parallel architecture is used in a bilayer distribution system. It is made up of an alternating current layer which provides aids to the system loads and an embedded direct current layer that interfaces the PV arrays with PHEVs. In [25-27],

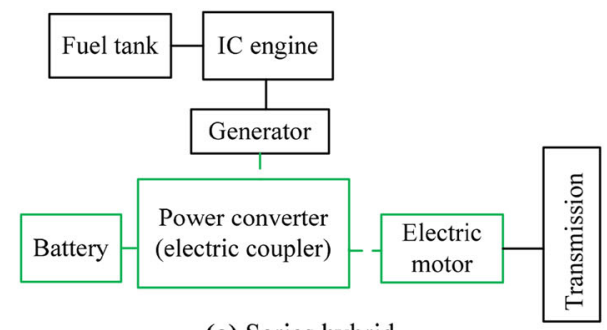

(a) Series hybrid

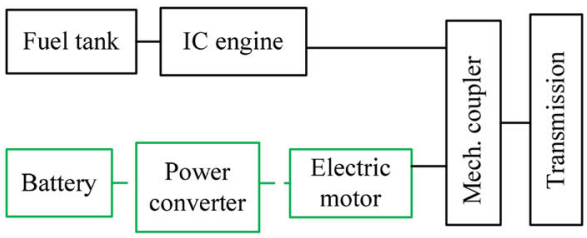

(b) Parallel hybridD

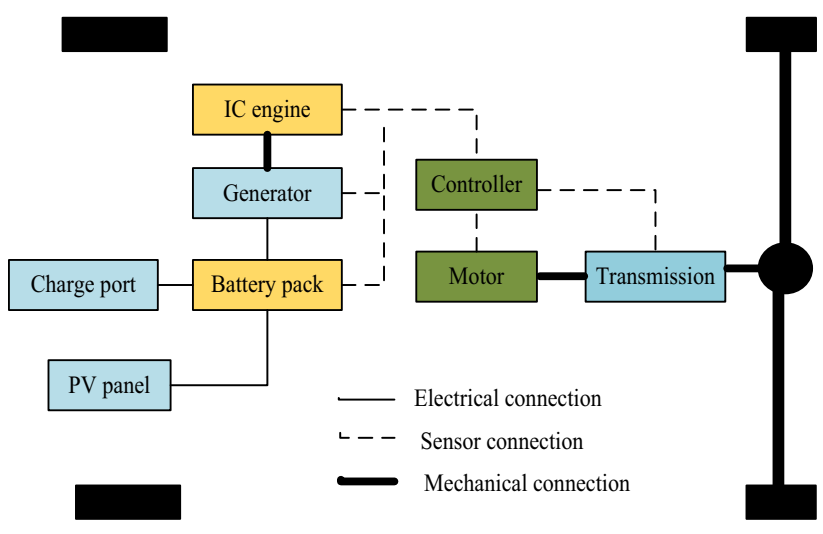

Fig. 3 Block diagram of PVHEV

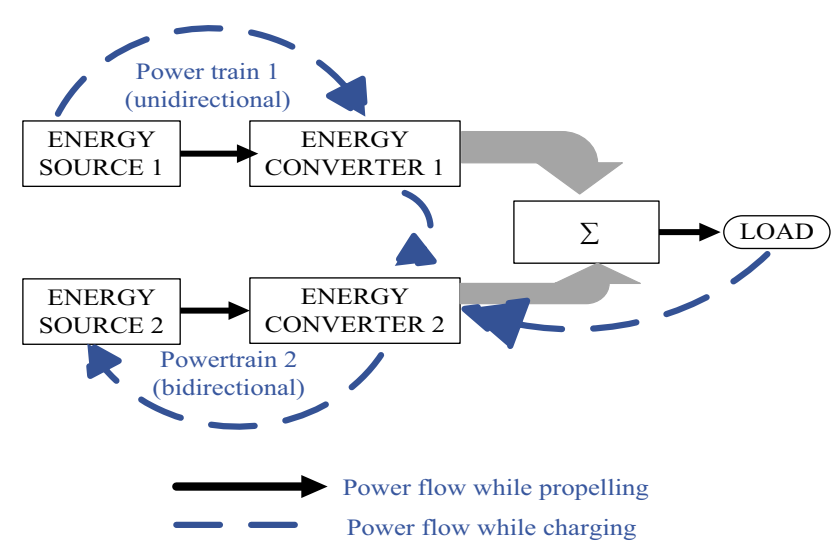

Fig. 4 Patterns of power flow

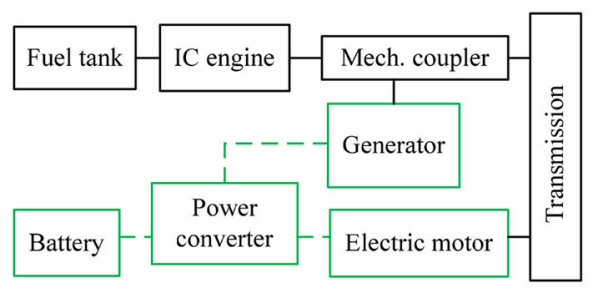

(c) Series-parallel hybrid

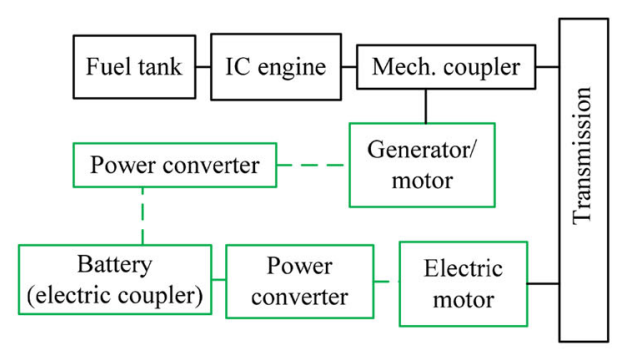

(d) Complex hybrid

Fig. 2 Various architectures of an HEV 


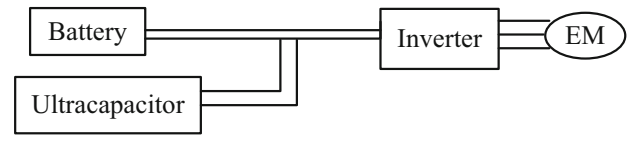

(a) Passive battery/UC configuration

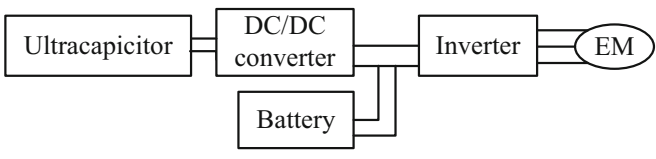

(c) Active cascaded UC/battery configuration

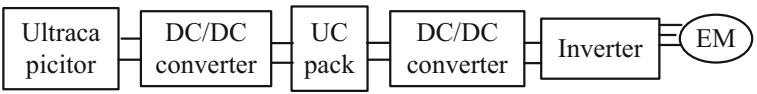

(e) Active cascaded configuration with two DC/DC converters

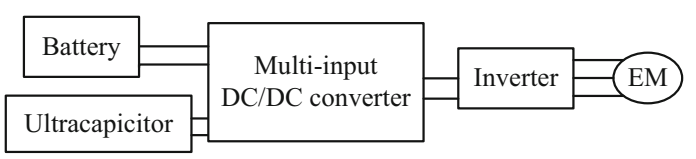

(g) Multi-input DC/DC converter configuration

Fig. 5 Various possible configuration of UC and battery [146]

the parallel architecture is employed for PHEV and its energy management is presented.

In [28], a model of the power split PHEV powertrain and a TTR hybrid electric powertrain was simulated and their prototypes were investigated based on various parameters. A quasi-static model was used to investigate and evaluate vehicle performance, fuel economy, emissions and supervisory control of the passenger car. A lowfrequency vehicle powertrain dynamics model was used to evaluate the vehicle dynamics, acceleration and braking performance of a racecar.

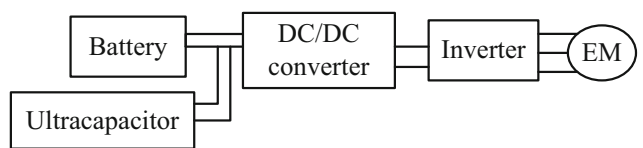

(b) Passive cascaded battery/UC configuration

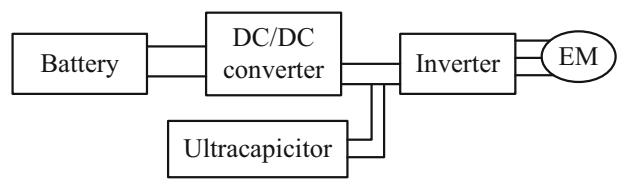

(d) Active cascaded battery/UC configuration

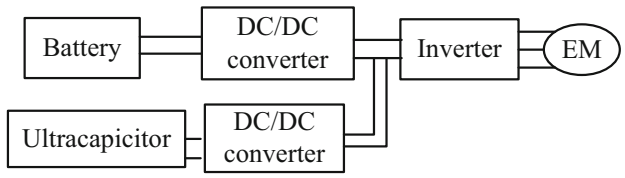

(f) Multiple DC/DC converter configuration
Based on the literature, a summary giving various architectures and their application is given in Table 2. Table 3 gives the comparison of emissions for EV and HEVs for FTP-75 urban, federal highway and commuter driving cycles. Table 4 provides a brief summary of these architectures.

There are various architectures available for HEVs, but since the complex hybrid involves bidirectional power flow, it is more suitable and beneficial compared to the rest.

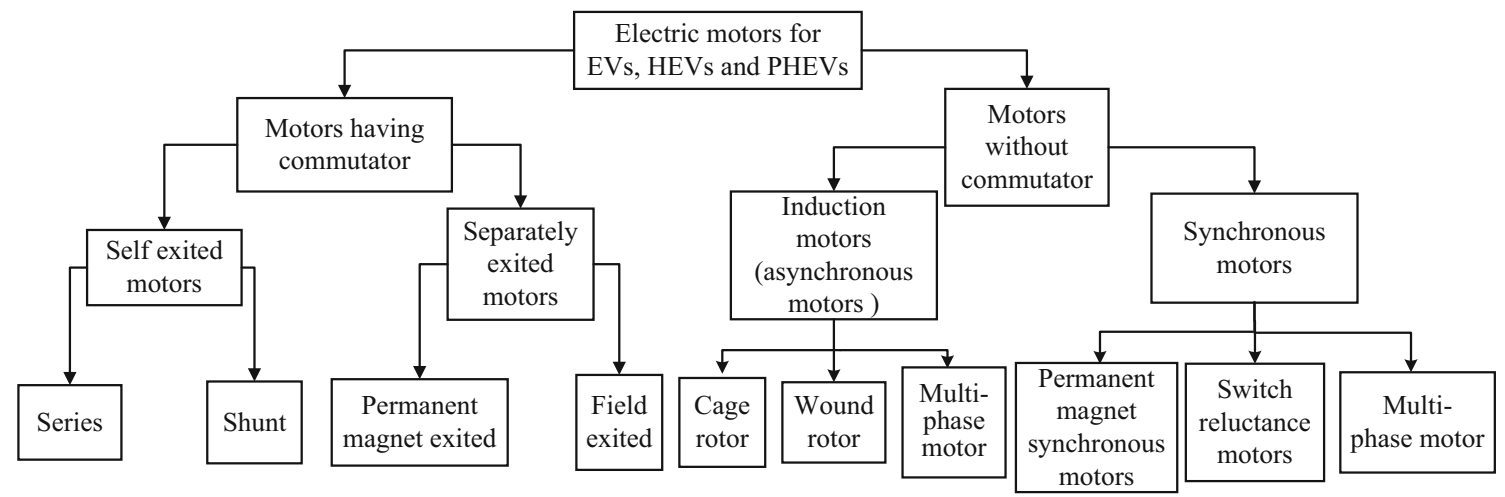

Fig. 6 Motor hierarchy 


\section{Bidirectional DC/AC converter}

Power converters are proliferated in all kind of applications to increase controllability and efficiency in automotive applications [30]. The bidirectional converter is essential in hybrid vehicles to convert DC from the battery/UC/fuel cell $(\mathrm{FC})$ or their combination into $\mathrm{AC}$ that is given to the motor drive. An extensive research has been carried out on DC/AC converters including single-stage single-phase [31], single-stage three-phase [32] or zero voltage switching inverters [33]. The various motor drives used in EV and HEV have been proposed in [34-45].

There are various topologies of traction inverters such as voltage source inverter (VSI), current source inverter (CSI), impedance source converter (ZSI) and soft switching [46]. These are described below.

\subsection{Current source inverter}

The CSI can be used for the speed control of AC motors, especially induction motors with varying load torque. The following are the types of CSI:

1. single-phase CSI,

2. auto-sequential commutated mode single-phase inverter (ASCI) and

3. three-phase CSI.

Advantages:

1. The circuit for CSI is simple. It uses only convertergrade thyristor having reverse-blocking capability and is able to withstand high-voltage spikes during commutation.

2. An output short-circuit or simultaneous conduction in an inverter arm is controlled by the 'controlled current source' used here, i.e., a current-limited voltage source in series with a large inductance.

3. The converter/inverter combined configuration has an inherent four-quadrant operation capability without any extra power component.

Disadvantages:

1. It suffers from the drawback of having limited operating frequency and hence cannot be used for uninterruptible power supply systems.

2. At light loads and high frequency, these inverters have sluggish performance and stability problems.

These inverters can be divided into two categories: one is to reduce switch count, and another is to reduce capacitance for HEVs. The reduced switch scheme faces the challenge of cost and efficiency, whereas reduced capacitance reduces the cost and improves the power density of the traction inverter. Wu et al. [47] proposed a CSI with interior permanent magnet machine, as it increases the constant-power operation regions due to voltage-boosting function. The CSI for medium- and high-power induction machines was studied in [48-54]. A novel space vector pulse width amplitude modulation (SVPWAM) method for a buck-boost CSI was proposed in [55]. Due to this technique, the switching loss had reduced by $60 \%$. Furthermore, the power density increased by a factor of $2-3$. A new type of control strategy known as the nouveau for CSI in battery-driven electric vehicle (BEV) has been proposed in [56] for better harmonic performance of the electrical machine. In [57], a method to switch off an interior permanent magnet synchronous motor (IPMSM) by using a CSI inverter in the event of a malfunction in a BEV has been presented.

\subsection{Voltage source inverter}

The VSI can be used practically in both single- and threephase applications. VSIs have good speed range, multiple motor controls from a single unit and a simple regulator design. In addition, there are some disadvantages of the VSI; e.g., the power factor decreases as the speed decreases, and it induces harmonics, cogging and jerky start and stop motions. The types, advantages and disadvantages of VSI are as below:

Types of VSI:

1. single-phase half-bridge inverter,

2. single-phase full-bridge inverter and

3. three-phase VSI.

Advantages:

1. low-power consumption and high-energy efficiency up to $90 \%$,

2. high-power handling capability,

3. no temperature variation- and aging-caused drifting or degradation in linearity,

4. easy to implement and control and

5. compatible with today's digital controller.

Disadvantages:

1. attenuation of the fundamental component of the waveform;

2. drastically increases switching frequencies and hence creates stresses on switching devices;

3. generation of harmonic components.

Liu et al. [58] selected an advanced film capacitor to replace the conventional electrolytic bulk capacitors for EV applications. In [59], an adaptive flux observer to adjust itself by online estimation of DC-link voltage and rotor resistance has been proposed for VSI-based induction 
Table 1 Saving in fuel consumption in some top models

\begin{tabular}{lllc}
\hline Technology & $\begin{array}{l}\text { Nonhybrid/nonelectric base } \\
\text { model (BEE* fuel efficiency } \\
\text { star rating) }\end{array}$ & $\begin{array}{l}\text { Hybrid/electric model } \\
\text { (BEE fuel efficiency } \\
\text { star rating) }\end{array}$ & $\begin{array}{l}\text { Gasoline equivalent } \\
\text { fuel consumption reduction } \\
\text { over base model }\end{array}$ \\
\hline Diesel-based mild hybrid & Maruti Ciaz VDI (5 star) & Maruti Ciaz VDI-shvs (5 star) & $7 \%$ \\
Diesel-based mild hybrid & Maruti Ertiga VDI (4 star) & Maruti Ertiga VDI-shvs (5 star) & $15 \%$ \\
Gasoline based strong hybrid & Toyota Camry at 2.5 1 (2 star) & Toyota Camry hybrid (5 star) & $32 \%$ \\
Battery-operated electric & Mahindra Verito d2 (4 star) & Mahindra E-verito d2 (5 star) & $68 \%$ \\
Battery-operated electric & - & Mahindra e2o (5 star) & - \\
\hline
\end{tabular}

*Bureau of Energy Efficiency

Table 2 Summary of architectures and their application

\begin{tabular}{lllll}
\hline Architecture & Complexity & Efficiency & Hybridization & Computation time/mathematical complexity \\
\hline Series & 1 & 1 & Full HEV and plug-in HEV & 1 \\
Parallel & 2 & 2 & Micro-, mild and full HEV & 2 \\
Series-parallel & 3 & 3 & Full HEV and plug-in HEV & 3 \\
\hline
\end{tabular}

1-low, 2-medium, 3-high

Table 3 Comparison of emission for different driving cycles [29]

\begin{tabular}{lllll}
\hline Parameters & Conventional & EV & Series hybrid & Parallel hybrid \\
\hline Control complexity & NA & Simple & Medium & Complex \\
Weight $(\mathrm{kg})$ & Very low & High & Medium & Low \\
NOx $(\mathrm{g} / \mathrm{km})$ & High & NA & Medium & Low \\
$\mathrm{CO}(\mathrm{g} / \mathrm{km})$ & High & NA & Medium & Low \\
HC & High & NA & Low & Medium \\
Fuel consumption $(\mathrm{km} / \mathrm{L})$ & High & NA & Medium & Low \\
Amount of energy supplied or depleted $(\mathrm{MJ})$ & NA & Low & Medium & High \\
\hline
\end{tabular}

NA not applied

motor (IM) in HEVs. The proposed observer is capable of obtaining simultaneous flux and DC-link voltage observation with online tuning of rotor resistance. Feng et al. [60] proposed a current injection-based online parameter and VSI nonlinearity estimation method for permanent magnet synchronous motor (PMSM) drives in EVs. The nonlinearity of VSI in HEV is discussed in [61]. A new inverter design based on the silicon carbide-based semiconductor devices was proposed to fulfill the power and temperature requirements of EVs in [62]. The impact of various modulation schemes on DC-link capacitor of VSI for HEV has been discussed in [63].

\subsection{Impedance source inverter}

Impendence source inverter (also called Z-source inverter, ZSI for short) has been considered an efficient candidate in vehicle applications such as drive system reliability, which
Table 4 Summary on architectures

\begin{tabular}{lllll}
\hline Architecture & Loss & Efficiency & Complexity & $\begin{array}{l}\text { Sizing of } \\
\text { component }\end{array}$ \\
\hline Series & 4 & 1 & 1 & 4 \\
Parallel & 3 & 2 & 2 & 3 \\
Series- & 2 & 3 & 3 & 2 \\
$\quad$ parallel & & & & 2 \\
Complex & 1 & 4 & 4 & 2 \\
\hline
\end{tabular}

4-very high, 3-high, 2-moderate and 1-minimum

leads to an increase in the range of inverter output. The ZSI is one of the most promising power electronics converter topologies suitable for motor drive applications. It has the properties of buck and boost in single-stage conversion. A special $\mathrm{Z}$ network composed of two capacitors and two inductors connected to the well-known three-phase inverter bridge and allows working in buck or boost mode using the 
shoot-through state. The ZSI improves the stability and safety of a brushless DC (BLDC) motor drive system under complex conditions. The following are the advantages of ZSI:

1. Provides desired AC voltage output regardless of the input voltage.

2. Yields high-voltage utility factor.

3. Overcomes voltage sags without any additional circuits.

4. Minimizes the motor ratings to deliver required power.

5. Improves the power factor and reduces harmonic current and common mode voltage of the line.

There are three topologies of ZSIs, namely basic, bidirectional and high-performance ZSI [64]. Replacement of the input diode by a bidirectional switch in the basic version results in bidirectional ZSI topology. The bidirectional ZSI is able to exchange energy between AC and DC energy storage. Being a basic topology, the variable frequency (VF) ZSI cannot work in regenerative mode and hence cannot charge the battery due to which the output voltage is low [65]. However, the continuous input current by VF-ZSI is suitable for photovoltaic (PV) applications. To perform rectangular wave modulation for motor drive control, an improved circuit topology of ZSI depending on the drive condition of the H/EV has been discussed in [66]. Dong et al. [67] have developed current-fed quasi-ZSI (CF-qZSI) with high efficiency by using reverse-blocking IGBT for HEV application. CF-qZSI is able to achieve bidirectional power flow and voltage buck operation as it has a diode and an LC network in its design.

The improvements in the heat transfer capabilities of power module technologies are still inadequate, and a paradigm shift is needed in order to achieve the cost reduction and meet the power density challenges of the $\mathrm{H} / \mathrm{EV}$ inverters [68]. The sustainability of inverters at very high temperature $\left(105^{\circ} \mathrm{C}\right)$ while operating at high efficiency is another issue to be addressed [69]. The $900 \mathrm{~V} \mathrm{SiC}$
MOSFET technology in the inverter reduces the energy losses and is beneficial in the mild city-style drive cycles [70]. Its application in multiphase motor drive system not only reduces power loss in the inverter but also permits the use of a smaller DC-link capacitor [71]. A high-capacity compact power module (J1 series) has been developed with compact size, high performance, lightweight and low selfinductance [72].

Another bidirectional DC/AC converter has been proposed for HEV applications, which can be used as a single input single/multiple output. The reduction in current ripple by carrier modulation method proposed in [73] leads to the reduction of DC capacitance and voltage ripple. The ripple reduction was achieved in HEV applications by using DC-link capacitor and carrier modulation technique $[74,75]$. The synergetic battery pack (SBP) inverter was also introduced for $\mathrm{H} / \mathrm{EV}$ applications. It has the advantage of using voltage semiconductor devices and hence improves the stability. In the SBP inverter, only one-stage conversion takes place and hence results in lesser losses and reduces the cost [76]. A pulse amplitude modulation (PAM) inverter was introduced in HEV to obtain high performance [77-82]. A fault-tolerant 4-leg topology was proposed in [83]. The quasi-ZSI (q-ZSI) [84] can buck and boost the voltage and provide the bidirectional power flow. In $[85,86]$, the modified space vector pulse width modulation with different pulse width modulation (PWM) sequences was applied, which led to different current ripples, switching loss, total harmonic distortion and voltage spike on the switching devices. Therefore, switching sequence and choice of PWM are important [87-89]. The strategy proposed in [90-92] allows the PMSM to work as inductors of the boost converter. This technique reduces the current ripple, thermal stress under heavy load and boosts the output.

An important criterion for deciding the size of a 3-phase PWM converter is cooling. A novel method is to have a power module concept with double-sided chip cooling

Table 5 Comparison of various topologies of the HESS [146]

\begin{tabular}{llc}
\hline Topologies & Advantages & Disadvantages \\
\hline $\begin{array}{l}\text { Isolated topology in Fig. 5b } \\
\text { Isolated topology in Fig. 5c }\end{array}$ & $\begin{array}{c}\text { Higher galvanic isolation, higher-voltage } \\
\text { conversion ratios }\end{array}$ & $\begin{array}{c}\text { Bulky, heavy, costly magnetic core, higher EMI, } \\
\text { higher-voltage stress across switches }\end{array}$ \\
$\begin{array}{l}\text { Isolated topology in Fig. 5d } \\
\text { Nonisolated topology in Fig. 5e }\end{array}$ & Lower transfer capacitor voltage rating \\
Nonisolated topology in Fig. 5f & Reduced input/output current ripples & $\begin{array}{c}\text { Two large inductors, discontinuous output } \\
\text { current, a larger output capacitor and a higher } \\
\text { switch/diode voltage rating }\end{array}$ \\
Nonisolated topology in Fig. 5g & $\begin{array}{c}\text { One small inductor no transfer capacitor voltage, } \\
\text { lower switch/diode voltage ratings, lower } \\
\text { capacitor voltage ratings }\end{array}$ & $\begin{array}{c}\text { Discontinuous output current } \\
\text { switching/conduction losses }\end{array}$ \\
\hline
\end{tabular}


Table 6 Comparison of various motors used in HEV [151]

\begin{tabular}{|c|c|c|c|c|}
\hline & Brushless DC & PM & Switched reluctance & Polyphase induction \\
\hline Type & $\mathrm{AC}$ & $\mathrm{DC}$ & $\mathrm{AC}$ & $\mathrm{AC}$ \\
\hline Family & Synchronous excited PM & Separately excited & Synchronous unexcited & $\begin{array}{l}\text { Induction slip ring } \\
\text { squirrel cage }\end{array}$ \\
\hline Power to rotor & PM & $\mathrm{DC}$ & Induced & Induced \\
\hline Power to stator & Pulsed DC & PM & Pulsed DC & $\mathrm{AC}$ \\
\hline Overall cost & High & Medium & Medium & Medium \\
\hline Weight & Low & Medium & Medium & Medium \\
\hline Commutation method & Internal electronic & Mechanical commutation & External electronic & External electronic \\
\hline Controller cost & Very high & Medium & High & High \\
\hline Pros & $\begin{array}{l}\text { Outstanding torque and speed, } \\
\text { fast responses, tremendous } \\
\text { power and long life }\end{array}$ & High starting torque & $\begin{array}{l}\text { Low inertia can be tailored } \\
\text { for specific applications } \\
\text { and runs cool }\end{array}$ & High efficiency \\
\hline Cons & $\begin{array}{l}\text { Very expensive, limited } \\
\text { economy to small-sized } \\
\text { motors }\end{array}$ & $\begin{array}{l}\text { Susceptible to damage if } \\
\text { dropped, requires } \\
\text { maintenance, bulky and } \\
\text { limited rotation speed }\end{array}$ & $\begin{array}{l}\text { Not very power full, ripple } \\
\text { in torque and requires } \\
\text { position sensing }\end{array}$ & Expensive controller \\
\hline $\begin{array}{l}\text { Maintenance } \\
\text { requirement }\end{array}$ & Low & Brushes wear & Low & Low \\
\hline Speed control method & Frequency dependent & PWM & Frequency dependent & Frequency dependent \\
\hline Starting torque & $>175 \%$ of rated torque & $>200 \%$ of rated torque & Up to $200 \%$ of rated torque & High \\
\hline Speed range & Excellent & $\begin{array}{l}\text { Limited by brushes, easy } \\
\text { control }\end{array}$ & Controllable & Controllable \\
\hline Efficiency & High & High & Less than PMDC & High \\
\hline Application & HEVs, EVs and ICVs & HEVs, EVs and ICVs & ICVs & HEVs, EVs and ICVs \\
\hline $\begin{array}{l}\text { Efficiency with motor } \\
\text { only }(\%)\end{array}$ & 80 & 97 & 94 & 90 \\
\hline $\begin{array}{l}\text { Efficiency with power } \\
\text { electronic devices } \\
\text { only }(\%)\end{array}$ & 98 & 93 & 90 & 93 \\
\hline $\begin{array}{l}\text { Efficiency with motor } \\
\text { and power } \\
\text { electronic devices } \\
(\%)\end{array}$ & 78 & 90 & 85 & 84 \\
\hline Examples & $\begin{array}{l}\text { Peugeot Citroen/Berlingo (psa) } \\
\text { (France) }\end{array}$ & $\begin{array}{l}\text { Nissan/Tino, Honda/Insight } \\
\text { (Japan), Toyota Prius } \\
\text { (Japan), etc. }\end{array}$ & $\begin{array}{l}\text { Holden/ECOmmodore } \\
\quad \text { (Australia) }\end{array}$ & $\begin{array}{l}\text { Renault/Kangoo } \\
\text { (France), Chevrolet/ } \\
\text { Silverado (USA), etc }\end{array}$ \\
\hline
\end{tabular}

Table 7 Comparison of MPPT algorithms used in HEVs

\begin{tabular}{lllll}
\hline MPPT technique & Convergence speed & Implementation complexity & Periodic tuning & Sensed parameters \\
\hline P\&O & Varies & Low & No & Voltage \\
IC & Varies & Medium & No & Voltage and current \\
Fractional $V_{\mathrm{oc}}$ & Medium & Low & Yes & Voltage \\
Fractional $I_{\mathrm{sc}}$ & Medium & Medium & Yes & Current \\
FLC & Fast & High & Yes & Varies \\
Neural network & Fast & High & Yes & Varies \\
\hline
\end{tabular}

which allows very high-power densities. In addition, lower stray inductance and package resistance improvements will enable high inverter efficiencies [93]. The dual-sided cooling discussed in [94] provides better cooling options in inverters. 
Table 8 Cost breakdown for different powertrain options (in EUR) [300]

\begin{tabular}{|c|c|c|c|c|c|c|c|}
\hline Costs type (in EUR, year 2020) & $\mathrm{ICV}$ & HEV & PHEV 15 & PHEV 30 & EREV & $\mathrm{BEV}$ & FCEV \\
\hline Purchase price (excluding $\mathrm{CO}_{2}$ penalties) & 27,946 & 29,963 & 30,805 & 31,941 & 37,093 & 36,390 & 46,456 \\
\hline Resale value & -9503 & $-11,916$ & $-12,252$ & $-12,704$ & $-14,756$ & $-10,335$ & $-15,809$ \\
\hline Net depreciation & 18,443 & 18,047 & 18,554 & 19,237 & 22,337 & 26,054 & 30,647 \\
\hline Energy cost & 4016 & 2142 & 1739 & 1564 & 1637 & 1235 & 2587 \\
\hline Maintenance and repair cost & 2892 & 2720 & 2704 & 2692 & 2124 & 2348 & 2548 \\
\hline Other operation cost (e.g., motor tax and inspection) & 330 & 160 & 160 & 160 & 160 & 53 & 53 \\
\hline Total cost of ownership & 25,680 & 23,069 & 23,157 & 23,653 & 26,257 & 29,690 & 35,835 \\
\hline
\end{tabular}

EREV extended range electric vehicle, also known as plug-in series HEV; PHEV 15 and PHEV 30: plug-in HEVs with two different battery sizes

Table 9 Comparison of various existing hybrid vehicles

\begin{tabular}{|c|c|c|c|c|c|c|c|c|c|}
\hline Vehicle & $\begin{array}{l}\text { Driving } \\
\text { range }\end{array}$ & Efficiency & Fuel type & $\begin{array}{l}\text { Overall } \\
\text { cost }\end{array}$ & Structure & Advantage & Disadvantage & ESS & $\begin{array}{l}\text { Driving } \\
\text { mode }\end{array}$ \\
\hline ICV & High & Low & Gasoline & High & Simple & $\begin{array}{l}\text { 1. Matured } \\
\text { technology } \\
\text { 2. Better } \\
\text { performance } \\
\text { 3. Simple and } \\
\text { reliable } \\
\text { 4. Commercialized }\end{array}$ & $\begin{array}{l}\text { 1. Harmful } \\
\text { emission } \\
\text { 2. Poor fuel } \\
\text { economy }\end{array}$ & Fuel tank & $\begin{array}{l}\text { City and } \\
\text { high } \\
\text { way }\end{array}$ \\
\hline $\mathrm{BEV}$ & Low & High & Electric & Low & Simple & $\begin{array}{l}\text { 1. Pollution free } \\
\text { 2. Efficient }\end{array}$ & $\begin{array}{l}\text { 1. Poor dynamic } \\
\text { response } \\
\text { 2. Recharge time is } \\
\text { high }\end{array}$ & $\begin{array}{l}\text { Battery and } \\
\text { ultracapacitor }\end{array}$ & City \\
\hline $\mathrm{HEV}$ & Medium & Low & Gasoline + electric & Medium & Medium & $\begin{array}{l}\text { 1. Low emission } \\
\text { 2. High fuel } \\
\text { economy } \\
\text { 3. Reliable and } \\
\text { durable }\end{array}$ & $\begin{array}{l}\text { 1. Bulky } \\
\text { 2. More number of } \\
\text { components }\end{array}$ & $\begin{array}{l}\text { Fuel tank, battery and } \\
\text { ultracapacitor }\end{array}$ & Highway \\
\hline PHEV & High & High & Gasoline + electric & Medium & Complex & $\begin{array}{l}\text { 1. Highly fuel } \\
\text { efficient } \\
\text { 2. Low emission } \\
\text { 3. V2G or G2V } \\
\text { capability } \\
\text { 4. Quiet and } \\
\text { smooth operation }\end{array}$ & $\begin{array}{l}\text { 1. High initial cost } \\
\text { 2. Impact on grid }\end{array}$ & $\begin{array}{l}\text { Fuel tank, battery and } \\
\text { ultracapacitor can be } \\
\text { charged from outlet }\end{array}$ & $\begin{array}{l}\text { City and } \\
\text { high } \\
\text { way }\end{array}$ \\
\hline PVHEV & High & High & Gasoline + electric & Low & Complex & $\begin{array}{l}\text { 1. Highly efficient. } \\
\text { 2. Low emission } \\
\text { and large size } \\
\text { 3. Quiet and } \\
\text { smooth operation } \\
\text { 4. Reliable }\end{array}$ & $\begin{array}{l}\text { 1. Very high initial } \\
\text { cost. } \\
\text { 2. Extra } \\
\text { components }\end{array}$ & $\begin{array}{l}\text { Fuel tank, PV panel, } \\
\text { battery and } \\
\text { ultracapacitor can be } \\
\text { charged from outlet }\end{array}$ & $\begin{array}{l}\text { City and } \\
\text { high } \\
\text { way }\end{array}$ \\
\hline
\end{tabular}

\section{Hybrid energy storage system}

The choice of ESS depends on various parameters, including charging speed, energy density, life expectancy, cost, weight and size $[95,96]$. The current trend indicates that batteries and UC remain as the main choices for ESS [97]. Batteries have low cost per watt hour, high energy density but short cycle life and low specific power, while UCs preserve high peak power, long cycle life, high cost per watt hour and low energy density [98-103]. The UCs are robust, have a quasi-infinite cycle life and can sustain highly dynamic power profiles [104, 105]. The UCs are also responsible to reduce the sulfation in lead acid batteries for EVs [106]. Furthermore, the UCs provide highfrequency and high-magnitude power, whereas the batteries fulfill low-frequency requirements. It is not possible for an individual energy storage device to fulfill all the requirements [107]. However, a combination of the two 
can help to overcome their drawbacks [108-113]. UCs tolerate the surges during the battery operation and maintain the DC-bus voltage, whereas the batteries maintain the SOC of the UCs. Therefore, the combination of these two will lead to high stability of the entire system $[114,115]$.

To protect EV batteries and extend their life, an UC is combined with them [116-119]. The sudden load variations are absorbed by the UC, and hence efficient use of the batteries can be achieved [120,121]. The batteries can be modeled with 1 resistance capacitor (RC) and multiple RC branches, and an UC is added to make it a HESS. The optimal power split between the battery and an UC is an important task and influences their sizing. Quite a few papers have discussed this power split, and they are briefly presented below.

The UC and battery parameters can be assessed using curve fitting techniques for desired cell responses. While designing ESS mechanisms like high temperature, over charge/discharge and under-/overvoltage protection schemes, cell balancing and their redistribution should be considered [122, 123]. To split the current between UC and battery, Karush-Kuhn-Tucker (KKT) and the neural network (NN)-based EMS are used in [124]. The NN-based EMS demonstrates better robustness and performance in terms of the battery state of health. However, KKT offers simpler implementation and excellent computation performance. The artificial neural network (ANN) is very useful in calculating the residual capacity of an UC [125].

The fuzzy logic (FL)-based EMS in a HESS for longer battery life was also adopted. Here, a battery lifetime degradation model was used to develop the relationship between the battery charge/discharge behavior and the impact on its lifetime [126, 127]. The power optimization in a parallel arrangement of battery and UC was carried out using superimposed DC-bus control system which had DCbus voltage, proportional integral (PI) controllers and a feed-forward load compensator [128, 129]. Wireless charging concept was used to charge the UC effectively in [130]. A rule-based control algorithm was proposed to effectively manage the UC's SOC and offload the current peaks from the battery in [131, 132]. Model predictive controller (MPC) was used to distribute the energy in a HESS in [133]. This scheme satisfied load demand and maintained the output voltage at the desired value.

In order to better utilize the high-power density of UCs, a logic threshold control strategy for HESS was proposed in EVs [134-137]. An adaptive FL-based EMS is used to determine the power split between the battery and the UC pack. An FL controller is used as it can easily manage the complex real-time control issues and does not need the knowledge of the driving cycle ahead of time. It maximizes the efficiency and minimizes the battery current variation [138]. A HESS linear quadratic regulator was designed to mitigate issues related to battery wear and peak power demands for EVs and HEVs [139].

The equivalent consumption minimization strategy is proposed to distribute the power between the battery and UC in a series HEV [140]. Other HESS like UC with the FC has also been adopted in few cases, and one of such combination is interfaced using the ant colony method in [141]. A dynamic MPC is designed for FC-UC hybrid, which maintains load side requirement and voltage across UC. The single MPC in outer loop is used to find the values of FC and UC currents which are used as references for inner PI control loop [142]. The implementation of HESS has at least three major advantages: cheaper batteries, increased autonomy and extended lifetime [143, 144].

There are various possible configurations to connect the HESS and the electric traction motor, which are given in Fig. 5. Also, a battery and UC can be interfaced by means of bidirectional DC/DC converter in many ways [145]. The topologies are mainly selected based on their advantages and disadvantages as tabulated in Table 5 . The boost halfbridge best meets the requirements of a bidirectional cell, thus suitable for battery/UC interface [146].

The passive connection given in Fig. 5a is the simplest configuration with both the battery pack and the UC directly connected to the motor drive without interfacing to a DC/DC converter. Regardless of the system simplicity, the absence of a control on the DC side is the main drawback of this system. This limitation is resolved in the controlled HESS [147] as presented in Fig. 5b, c. The UC is not directly connected to the DC bus, and the bidirectional DC/DC converter controls the power contribution from the UC. The optimal sizing of the DC/DC converter is the main issue here.

In active cascaded battery/UC topology shown in Fig. 5d, UC is directly connected to the terminal of an inverter, whereas the battery is connected through a DC/ DC converter. The UC acts as a buffer against a rapid power flow change. As a result, battery is protected and the energy flow can be effectively controlled. However, in this topology, UC voltage needs to be kept constant, limiting the working range of the UC. This topology was used in [148] to reduce the conduction and switching losses and to improve the accuracy.

A new concept having two semi-active configurations, i.e., a semi-active UC and a battery, has been postulated in [149]. A bidirectional nonisolated DC/DC converter performs energy control of one of the storage elements. In this control strategy, UC provides fast dynamic power, and the complement is provided by the battery bank [150], as shown in Fig. 5e.

In case of multi-DC/DC converter topology shown in Fig. 5f, the battery and UC are individually connected to the inverter terminal through their own DC/DC converter. 
This topology shows a good performance, especially for the controllability of current flow.

The two DC/DC converter required in topologies shown in Fig. 5e, $\mathrm{f}$ is replaced by a multi-input nonisolated bidirectional DC/DC converter [151]. This topology minimizes the losses and has been analyzed in [152].

The multi-input DC/DC converter is used for the integration of energy sources such as FC, PV and wind for EV applications [153]. The advantage of DC/DC converter is to have low component counts and a simplified structure. Since this converter is capable of operating in different modes of operation such as boost, buck and buck/boost, this topology attains an important role in the energy diversification of different sources in HEV applications [154]. A zero voltage transition buck-and-boost converter can also be employed for UC interface that guarantees soft switching condition for all semiconductor devices in EVs [155].

In [156], a three-level neutral point-clamped converter (NPC) is proposed to optimally couple UC and a battery pack. It minimizes the usage of battery pack in providing peak current in acceleration and deceleration modes. In [157], a half-bridge bidirectional DC/DC multi-input converter is chosen to link the battery and the UC.

\section{Motors}

There is an extensive need of advanced motors and generators to meet the aggressive targets in terms of efficiency, power density and cost of the drivetrain in HEVs. The specification of the motor/generator depends on its usage, like in light/medium/heavy duty vehicles, off/on highway vehicles and locomotives. The performance of the machine depends mainly on vehicle duty cycle, thermal characteristics and the cooling mechanism implemented. Invention of power converter topologies for drive control has advanced the traction systems for EVs over recent years. The classification of various motors used in traction is shown in Fig. 6. A brief literature review on the motors used for traction in EV/HEVs is presented below. A brief study on control methods of these motors is also presented at the end of this section.

\subsection{Switched reluctance motors}

These days, the switched reluctance motor (SRM) is receiving much attention in EV/HEV applications. These motors have various advantages such as easier control, rugged construction, better fault tolerance capability and outstanding torque-speed characteristics. An SRM is well suited for applications where constant power is required over a wide operating region. SRM is also reported with several drawbacks such as electromagnetic interference, torque ripple, high noise and requirement of a special convertor topology [158].

In order to overcome the drawbacks of SRM such as low torque/power density and high torque ripple, a novel modular (M)-SRM with hybrid magnetic paths for simple structure, low cost and improved dynamic performance has been presented for EV applications [159]. An average torque control of SRM for light EVs is proposed to control and estimate the average torque of the motor shaft in [160]. The Seeker optimization algorithm has been presented in [161] to minimize the torque ripple of SRM.

A multistage fast design methodology for SRM is presented in [162]. The process aims to determine the best speed at which the SRM would start in single-pulse mode operation. In [163], SRM was developed with a new propulsion system having good overall efficiency in the total speed range, especially in high speed and excellent generating performance. Generally, PI controllers are used for the speed control of SRM, but have drawbacks of high overshoot and settling time; hence, to overcome them, a fuzzy sliding mode controller has been presented in [164]. SRM is highly suitable to provide the maximum torque for a short time [165]. In [166], SRM has been constructed and test results are presented over the entire speed range and it has been concluded that the output power is significantly enhanced to $100 \mathrm{~kW}$ from $60 \mathrm{~kW}$ in a high-speed range (5400-13900 rpm) with the same outer diameter and the axial length of the IPMSM. A new design of SRM as a starter/generator for HEV has been presented in [167]. The results show that SRM is capable of starting the vehicle and charging the battery as well. A new modified fuzzy-PI controller is designed to control a high-power SRM, modeled by means of the finite element method (FEM) for HEV applications [168]. This ensures the best efficiencies over the specified operating range.

To improve the efficiency of SRM for HEV, the response surface method and multiobjective genetic algorithm (GA) are applied over various operating modes [169]. Considering the maximum torque capability and maximum power density, SRM seems to be the best candidate for HEV application [170]. In [171], an optimized controller for SRM to reduce undesirable torque ripples for EV and HEV has been discussed. An integrated multilevel converter fed by a modular front-end circuit in SRMs for PHEV has been presented in [172].

The high-speed capabilities of 6-slot/4-pole and 8 -slot/6-pole designs have been presented in [173]. The 6/4 designs yield $40 \%$ more power at high speed without exceeding the voltage and current ratings of the motors. The SRM definitely shows potential for superior performance to BLDC's and IM's [174]. A split converter-fed four-phase SRM drive to realize flexible integrated 
charging functions (DC and $\mathrm{AC}$ sources) has been presented for better fault tolerance in [175]. The features of SRM have been described keeping in view their application for vehicles [176].

\subsection{Brushless DC motors}

BLDC motors are theoretically the result of reversing the position of the stator and rotor of PM DC motors. Their main advantages are high efficiency, compactness and high energy density. In [177], a 5-phase brushless fault-tolerant hybrid-excitation motor was proposed for EV applications. In [178], BLDC was used for EV by means of a fuzzytuned PI speed control. In [179], a brushless dual-rotor flux switching permanent magnet motor was employed for PHEV application. A double-stator permanent magnet BLDC (PMBLDC) was engaged for HEV application in [180].

A position sensorless BLDC motor based on the sliding mode control has been presented in [181] for EV applications. The techniques based on flux-weakening control are complex and costly. To circumvent these problems a multispeed winding is designed with sensorless control and presented in [182]. The back electromotive force (EMF) signal of brushless in-wheel hubs can be exploited to simplify their antilock braking system (ABS) arrangement. The experimental results show that the sensorless wheel speed measurement accuracy of a BLDC motor with eight pole pairs is approximately $50 \%$ better than the ones produced by the commercial ABS sensor [183].

The integrated starter generator torque booster for a hybrid propulsion system has been presented in $[184,185]$. In [186], a promising doubly salient-BLDC generator for HEV application was proposed as it has low cost, high robustness and flexible control. The predictive controllerenabled BLDC motor drive has been presented to improve the motor current response in [187]. In [188], field weakening has been improved, which helps in vehicles where large constant/power speed ratio is required. Digital PWM control for a BLDC drive in both motoring and generating modes of operation is discussed in [189]. This control strategy is simple, robust, current sensorless and computationally less intensive. Chen and Cheng [190] used a lowvoltage BLDC motor/alternator with modified converter design in hybrid electric scooters. In [191], the magnetization analysis of the BLDC motor has been presented and it has been concluded that the post-assembly magnetization is preferred in order to overcome the problem of magnetic forces and ferrous debris. The magnetic field-modulated brushless double-rotor machine (MFM-BDRM) is composed of the stator, the modulating ring rotor and the PM HEVs. Compared with traditional double-rotor machines (DRMs), the MFM-BDRM shows more complicated electromechanical energy conversion relations, due to its special operating principle [192]. The influence of magnetic phase couplings on the performance of multiphase BLDC machines with overlapping phase winding configurations is investigated in [193]. A novel configuration of the BLDC motor with an integrated planetary gear train, which provides functional and structural integrations to overcome inherent drawbacks of traditional designs, has been presented in [194]. The performance of BLDC motor was evaluated in terms of rise time, setting time and overshoot using topologies like fuzzy, PI and their hybrid in [195]. It has been concluded that a hybrid controller is suitable for high-power applications, whereas a PI controller is promising for low-power applications. The generated output power of five-phase BLDC motor is improved under faulty conditions in HEVs [196, 197]. An efficient regenerative braking system in BLDC motor is presented for hybrid vehicles in [198].

\subsection{Permanent magnet synchronous motor}

PMSMs prove to be strong contenders to IM in HEV applications. Its benefits include lesser heating, higher power density and higher efficiency. That being said, PMSMs suffer from a major drawback of demagnetization due to armature reaction. In [199], the PM motor and IM were compared for HEV application with the help of advanced vehicle simulator (ADVISOR) tool and the results indicate superior performance of PM motors, in terms of standard performance indices such as traction capabilities and fuel efficiency. A PMSM shows better result for HEV when clubbed with HESS.

A novel PMSM drive system with a bidirectional ZSI is proposed and tested by keeping in view the feasibility and effectiveness for an EV system. The application of a bidirectional ZSI to PMSM drive system improves the reliability since it is a single-stage structure and the shootthrough states can no longer destroy the inverter [200]. The PMSM with ZSI and modified vector control considering DC-link capacitor is presented in [201]. To improve the efficiency of a PMSM, a loss optimization control strategy is proposed in [202]. A generalized predictive current control method combined with sliding mode disturbance compensation is proposed for PMSM to satisfy the requirement of fast response in EV system [203]. The hybrid PWM-based discontinuous modulation strategy with DC-link voltage balancing for a three-level NPC traction inverter is presented, and PMSM is considered for traction motor drive in [204]. A test bench has been developed using a surface-mounted PMSM to emulate various electrical machines to understand their real behavior [205, 206]. 
To prevent an increase in speed during emergency crash, high-voltage discharge of the capacitor for PMSM drive is presented in [207]. Six typical topologies of compoundstructure PMSM (CS-PMSMs) are proposed and evaluated in terms of torque density, manufacturability, heat-dissipating capability and magnetic coupling for an HEV system [208]. The virtual prototyping and optimization of PMSM for HEV drivetrains is presented in [209]. Zheng et al. [210] used an axial-axial flux CS-PMSM, which enables ICE to operate in the optimum efficiency region independent of road conditions. The robust shape model of PMSM for a large-sized HEV is presented in [211]. The numerical computations using the FEM are performed to build the lumped parameter model for PMSM system in [212]. The field-controlled PMSM is proposed for HEV applications in [213]. A new PMSM machine with increased power capability was proposed in [214] with two winding sets in which one of them is dedicated for generator operation and the other for output voltage regulation by flux weakening. To minimize the problem of coupling between $d$ and $q$ axes, a modified current control strategy of the flux-modulated CSPMSM has been presented in [215].

The PM-assisted synchronous reluctance motors for automotive applications have been examined in [216], but as they use rare earth PMs, the electric motors with less or no rare earth PMs are therefore presented. To reduce the cost of the machine, the flux switching of the PMSM has been presented in [217]. In order to avoid the fault in any component, an onboard diagnostic approach for PMSM drive system has been presented in [218]. Point of common coupling is used to obtain fast torque monitoring and highperformance operation of a PMSM in [219]. A fault-tolerant control system for high-performance PMSM drive is proposed in [220]. Unbalanced magnetic pull plays a key role in nonlinear dynamic behaviors of PMSM. The analysis indicates that these effects are caused by the interaction of the initial phases of forward and backward whirling motions [221]. Reference [222] presents a sensorless algorithm designated for the emergency control of an interior PMSM drive. Two topologies for PMSM (1. battery connected directly to inverter and 2 . connected through bidirectional converter) are compared, and it has been concluded that high efficiency of PMSM drive can be obtained by using the second topology [223]. In [224], the design principles of PMSMs for traction applications and its necessary boundary conditions, such as PM flux linkage level and the synchronous inductances, have been discussed; several different topologies capable of producing a low-speed peak torque have been also studied.

To avoid the catastrophic failure of the encoder and sensor, a novel backup universal sensor concept for PMSM with position and current estimation has been presented in [225]. An improved algorithm has been developed for obtaining the maximum torque by accounting the core loss, cross-coupling effect and temperature for PMSM drive [226].

\subsection{Induction motor}

IMs are widely accepted for the propulsion of EVs, due to their reliability, ruggedness, low maintenance and high efficiency. In addition, from a safety point of view, these motors get de-excited during fault in inverter [227]. IMs offer a higher power density and better efficiency when compared to the DC machine. IM provides a wide range of speed with good efficiency. Some of the usage of IMs in hybrid vehicles is briefed below.

The new design of IM for EVs was proposed with improved speed torque curve in [228]. The field-oriented control (FOC) algorithm needs accurate estimation of motor state variables in order to ensure full-torque performances and good efficiency of IM. For this purpose, a two-rotor resistance estimation method is presented in [229]. Reference [230] presents the motor condition monitoring for HEV and its review with focus on nine commonly used condition monitoring methods of IM. In [231], losses and temperature in IMs are considered and the effects of rotor materials and air-gap length on the performance of these motors are analyzed. It is concluded that the efficiency of the motor with a copper mouse cage rotor is considerably higher than that of the motor with an aluminum rotor. A new sensorless speed control technique for IM-driven EV using a model reference adaptive controller (MRAC) with a basic energy optimization technique known as golden section method has been presented in [232]. The proposed scheme is immune to the variation in stator resistance. The unique formation of the MRAC with the instantaneous and steady-state reactive power eliminates the requirement of any flux estimation in the process of speed estimation. In [233], an energy-efficient and speed-sensorless control scheme for IM of EV has been presented. The IM drive is designed, keeping in view the features like fast dynamic response, high efficiency and low cost. Furthermore, a loss minimization algorithm is associated with the main control strategy to ensure high IM drive efficiency.

An improved direct rotor FOC of seven-phase IM for HEV has been presented with FLC to filter the nonsequential current [234]. This minimizes the loss in IM, which adds to its advantages of high reliability, low cost and high power and torque density. The IPMSM is still an efficient and attractive machine for traction applications from efficiency and size perspective but with increased cost, mainly due to rare earth material [235].

A dual-current loop control algorithm has been proposed for HEV in [236]. The torque and air-gap flux of a doubly 
fed induction motor (DFIM) are controlled directly as compared to the singly fed permanent magnet. For IM, the torque-speed operation region for EV/HEV applications is nearly doubled with the proposed algorithm. A compact diagnostic algorithm is presented using advanced speed feedback error management technique for traction motor and generator faults in [237]. The issues addressed are sensor issues, vehicle vibration, hardware tolerances and environmental impacts like temperature, moisture and electromagnetic interferences. A single-electrical-port control scheme, for four-quadrant operation of cascaded DFIM, is proposed in [238], and a new hybrid cascaded $\mathrm{H}$-bridge multilevel inverter for IM has been proposed to improve torque control. An improved motor line-current reconstruction technique by software control for shaftsensorless EV and HEV propulsion drives has been presented in [239]. This strategy emphasizes on the minimization of the error caused in driveline current.

A new kind of IM called as induction motor with compound cage rotor (IMCCR) has been proposed in [240]. The IMCCR has been suggested as a better choice for the driving systems in EVs and PHEVs. The effects of ambient temperature and output load on motor thermal performance have been considered as well. Table 6 provides the comparison of various motors used in $\mathrm{HEV}$ applications.

Based on the literature survey given above, it is found that there is growing interest in the development of advanced traction motors for hybrid vehicles and many traction motors are available in market. However, considering the trade-off based on various parameters like performance, robustness, reliability and cost, the choice is often between IM and permanent magnet AC motor.

\subsection{Control of traction motors}

A brief study has been carried out on the various methods of controlling the traction motors used in hybrid/electric vehicles and summarized as below:

The driving characteristics of a PM-type antidirectionaltwin-rotary (ADTR) motor on the EV driving simulator and traction control for an EV using ADTR motor have been presented in [241]. There are three excitation sources, namely permanent magnetic, armature and axial coils in the motor. Control of these excitation sources to make the motor run in different modes for vehicle applications has been demonstrated [242]. A novel algorithm for designing the set of PI/PID controllers for stabilizing the current and speed loops of a high-speed and high-power flywheel energy storage system using a PMSM is demonstrated in [243]. The improved speed tracking performance of a fuzzy-based indirect FOC of IM drives in comparison with a conventional PI control in HEV applications is presented in [244]. In [245], a stator flux-oriented (SFO) control scheme of IM using variable-saturation regulators is proposed. The traditional SFO control scheme consists of the d-axis current component, torque, stator flux and speed loops with four PI-type controllers. This control scheme uses two regulators with variable saturation in such a way that the maximum DC-bus voltage utilization is reached and overcurrent problems are prevented. A fuzzy adaptive controller to minimize harmonics introduced by the multilevel converter in traction drives is presented in [246]. A combined control structure of IPMSMs to achieve true maximum voltage utilization is proposed in [247]. The hybrid structure provided a smooth transition from current vector control to modulating voltage-scaled controller mode by deactivating the current regulator in the fluxweakening region. A pressure command control method of engine clutch in a parallel-type HEV is demonstrated in [248], where a dynamic model of an HEV powertrain was also constructed to launch operation with engine power only. A review on different motors used to propel EVs, their control techniques and rotor speed estimation using sensorless methods has been presented in [249].

Direct torque control (DTC) in an IM to achieve better performance has been shown in [250]. As the motor speed varies, the switching frequency also varies, and the maximum sampling frequency is used in DTC. The motor structure and torque equation of a novel claw pole-type half-wave-rectified variable field flux motor, as well as the motor design parameters, are described in [251]. The influence of the rotor structure on the torque characteristic was also evaluated using 3D-FEM. Reference [252] presents a synchronous homopolar motor, which is suitable for sensorless operation over its entire speed range, including zero speed. This ability is necessary for the traction drives, the reliability of which is currently limited due to the presence of the rotor position encoder needed for operation at low speeds. In [253], an attempt was made to build a fast response overvoltage-protecting circuit for traction IPMSM. A good work on the control of salient-pole PMSM for traction in hybrid vehicles has been presented in [254]. In [255], a consensus based on the total amount of cooperative tracking control has been developed to maintain total torque needed for traction. Case studies, particularly with system architecture (sliding mode and PID control methods), extremum-seeking algorithm for the maximum tire-road friction and the corresponding slip value, and experimental validation of the tire model used in the controller were discussed in [256]. The analysis of the three topologies for on-board HESS in EV applications modeled with energetic microscopic representation for voltage stability has been proposed in [257]. A dynamic model, design and novel control strategy for ecotractions supplied by wind generator-supercapacitor hybrid power systems 
have been developed in [258]. A novel efficiency improvement method using loss models and gold section search in an IPMSM traction system in EVs has been presented in [259]. The loss models of the IPMSM and the inverter were considered here, and a $2.7 \%$ increment in the overall efficiency was recorded. A model reference adaptive system-based estimation algorithm to calculate the rotor resistance of an IM working under dynamic conditions has been reported in [260]. An advanced strategy for life extending control of PMSMs traction drive system in rail vehicles that evaluates and compares the IGBTs damage under different flux conditions offline, has been proposed in [261]. A supertwisting algorithm (STA)-based control scheme for vehicle traction control has been proposed in [262]. The controller is a combination of the STA control law and a nonlinearity observer. The control law was designed based on a sliding mode control method, but the switching control part was replaced with a STA. An integrated vehicle and wheel stability controller which is designed using MPC technique has been proposed in [263]. The prediction model consists of a double-track vehicle model augmented with the wheel dynamics. A novel adaptive wheel control algorithm with slip optimization, considering a balance between maximizing the traction and minimizing the energy consumption, depending on surface conditions has been proposed in [264]. A detailed review on energy optimization strategies in HEVs is given in [3].

\section{MPPT algorithms used in HEVs}

With the growing demand for switching over to renewable energy resources, PV technology is charging ahead of the other alternatives. The various salient features of it being noiseless, pollution free, immune to direct contamination and its simplicity in operation help make it the preferred choice. The various structures of PV systems and their suitability in hybrid vehicles have been discussed in [265-269].

The I-V characteristics of PV cells are nonlinear, and there exists only one maximum power point (MPP) [270]. By interfacing the power, electronic devices with PV system, the efficiency can be increased along with MPP controller.

Many algorithms have been put forward to track this MPP, but among all, constant voltage tracking method is the most traditional method but has limitations during varying temperature. To overcome them, perturb and observe (P\&O) and incremental conductance (IC) methods are most widely used.

In case of $\mathrm{P} \& \mathrm{O}$, the load impedance varies periodically and senses the change in the direction of power, whereas in
IC, $\frac{\mathrm{d} p}{\mathrm{~d} v}$ is monitored to detect whether MPP has reached, where $p$ is the power and $v$ the voltage. In $\mathrm{P} \& \mathrm{O}$, the system oscillates near MPP; hence, the system works, inefficiently [271]. The IC algorithm is the procedure where the voltage and current curves provide the maximum power level [272]. The advantage with IC is its responsiveness to changing atmospheric conditions, whereas $\mathrm{P} \& \mathrm{O}$ benefits from being more straightforward to implement [273].

A simple charging algorithm with $\mathrm{P} \& \mathrm{O}$ MPPT was proposed for PVHEV in [274]. This is used to extract the maximum power with the help of a boost converter. The charging algorithm drives the converter in constant current and constant voltage mode as needed. The $\mathrm{P} \& \mathrm{O}$ algorithm has also been designed for PVHEV in [275].

An MPPT control algorithm which does not require a current sensing device has been presented for HEV applications in [276]. In this algorithm, MPP can be determined by the PV voltage and switching duty ratio of the converter. In [277], a small-sized PV cell and other hardware components were selected to reduce power loss and cost and to obtain high efficiency. In [278], a solar-thermoelectric hybrid system for HEVs was proposed with $\mathrm{P} \& \mathrm{O}-$ based MPPT. This method is capable of tracking the global MPP with reduced hardware cost [279]. The ANN-based MPPT in PVHEVs was also used. An offline ANN, trained using the backpropagation and gradient descent momentum algorithm, can be used for online estimation of the reference voltage for the feed-forward loop [280]. In [281], it is proposed that one should use $\mathrm{P} \& \mathrm{O}$ algorithm when the vehicle is parked and voltage-based MPPT algorithm is suitable while driving.

The MPPT algorithms, namely P\&O, IC and only current, are compared in terms of energy performances in ambient conditions, and IC has proved to be better [282]. For comparison, PV modules were mounted on a moving platform, designed to simulate insulations received by solar systems on a moving vehicle.

A modified $\mathrm{P} \& \mathrm{O}$ algorithm has been proposed to obtain fast transient response with high stability for variations in solar irradiance [283]. P\&O- as well as IC-based techniques can be used to handle variable solar irradiance. They provide an optimal solution and a realistic driving scenario. Voltage balancing control is very useful as it allows an independent source for every independent MPPT in a distributed MPPT (DMPPT). When compared to centralized MPPT (CMPPT), the DMPPT offers $6.9-11.1 \%$ improvements in annual energy [284]. The single-ended primary inductor converter and estimated $\mathrm{P} \& \mathrm{O}$ were used for charging the battery efficiently, which prolongs the battery life [285]. MPPT algorithms based on the ant colony optimization, FL, ANN, GA and PSO, have been applied to PV systems under changing irradiance 
conditions. A new type of algorithm, namely firefly algorithm, was also introduced in [286].

The PHEV loads should be given due consideration while designing a grid-connected residential PV system. The PV arrays and battery packs can be connected in a cascaded manner to power the load. A DC/DC converter can be used to regulate the voltage of the PV arrays by MPPT using the IC method [287]. In grid-connected mode, PV works at its MPP and EV works in the charging mode. However, when the microgrid gets isolated from the utility grid, both PV and EV should deliver active and reactive powers to feed the loads [288]. Table 7 provides the comparison between various MPPT algorithms, which have been used in HEVs. ANN and FL are trending these days because of their advantages over others.

\section{HEV: the flipside}

Ever since Lohner-Porsche, the first HEV, was developed in 1901, the automobile industry has come a long way. In the recent years, HEV technology has gained tremendous boost in terms of research and development. There is a general sense of optimism in the industry in regard to this new technology. While discussing the many advantages of HEV, often the shortcomings are overlooked. This technology is still in a relative inchoate state and has certain below-mentioned inherent shortcomings that need addressing in order to become a mainstream product.

\subsection{Shortcoming}

1. Limited range An HEV has a comparatively restricted range. Considering that an HEV ought to generate minimal amount of energy from the ICE, the distance per charge is relatively small. There have been improvements apropos of this variable. Further, an HEV requires a minimum of $30 \mathrm{~min}$ to charge fully, whereas a traditional car would require barely five minutes to fill the complete tank.

2. Low power A traditional vehicle is equipped with a powerful ICE which allows it to provide tremendous speed and torque. In HEV, the combination of ICE, $\mathrm{EM}$ and pack of batteries makes it bulky and eats up the extra space. In the bid to reduce the weight and cost, an HEV is equipped with a weaker engine and smaller motor, which gives less speed and torque. Owing to this fact, faster cars have not been able to transit to this eco-friendly technology. There have been attempts to break this image, with a prominent example being Tesla's Model S vehicle, but the cost of the car is well beyond the common man's budget.
Adding fuel to the fire, an ICE is more durable than a motor which has many sensitive components.

3. Expensive The major concern that holds back the buyer's intention to purchase a hybrid vehicle is its cost that makes it \$5000-\$10000 costlier than conventional cars. But, the features of HEV like lower running cost and tax exemptions can compensate for this rise in cost up to large extent.

4. Maintenance costs The complex structure of HEV leads to high maintenance cost along with it and also gives rise to the need of highly skilled technicians and mechanics for repair.

5. Batteries Considered to be the weakest link in the chain, the battery required to store energy has always posed a challenge in HEV technology. Lithium-ionbased batteries are the most common batteries used in HEVs owing to its high energy density. But such batteries invite a whole set of problems, such as its high sensitivity to external environment, weight and cost. Compared to the traditional ICE, a battery is more susceptible to variations in temperature and is heavier. The final nail in the coffin is that the materials used in the creation of the battery itself are hazardous to the environment, hence vitiating the ultimate objective of being a green technology. The risk of human life during an accident is exacerbated due to the additional risk of electrocution from the batteries present in an HEV.

6. Security A HEV requires a controller for the optimum usage of ICE and electric motor power trains. With the increased dependence on smart solutions, security proves to be an ever present danger. Remote exploitation may result in illegal access to unsavory people. It may result in huge losses for an individual if not wary. Unlike a traditional ICE which still requires physical contact to stop or disable a vehicle, an HEV is vulnerable to remote attempts. As such great precautions and protocols need to be developed to keep consumers safe.

7. Critical analysis Several critics also claim that an HEV simply delays the inevitable due to its continued consumption of fossil fuels. In order to provide more power or increase the distance, an ICE is coupled with the motor. As such, an HEV only reduces the rate of fuel burning in ICE. With current estimates indicating the exhaustion of fossil fuels in the recent future, some critics are skeptical of the utility of HEVs $[289,290]$.

\subsection{Scope for improvements}

There are many fronts where this technology can grow, be it in the adaptation, dissemination or penetration of HEV in 
the market. Being quite advantageous over conventional vehicles, it has some weaknesses in terms of efficiency, refueling, cost and many others. Some important thrusts of focus are listed below.

1. Battery issues The battery plays a vital role in HEV performance. They are quite heavy and expensive and thus impact the cost of HEVs. The performance of a battery is affected by temperature variations; therefore, an efficient battery management system is required. It needs long charging time and is sensitive to over/ undercharge. Number of charge/discharge cycles decides the durability of battery. Further, disposal of toxic waste of battery is a big issue. Resolving these issues will allow the BEVs to run on the road.

2. Public awareness Public awareness and participation is very crucial to infiltrate HEVs in their lives. Various media and education can make people conscious about the advantages of this alternate transport. Participation of government, private players and cost-effective schemes will encourage consumers to use hybrid vehicles.

3. Smart charging infrastructure The charging infrastructure needs to be built at regular intervals so that these vehicles can be used for long journeys.

4. Impact on grid EVs and PHEVs mostly are charged by being plugged into the power outlet continuously for several hours. So, increase in these vehicles will increase the load on grid and power system performance issues. Hence, the need for extra generating units will arise. The electric power available in vehicles can also be banked at the grid using vehicle to grid (V2G) concept which is relatively unexplored at present. This concept works on the balancing of the 'off-peak' and 'peak' demands.

5. Cost Due to high prices of the batteries used in HEVs, EVs and PHEVs, these vehicles are not affordable to middle-income groups who comprise the major portion of the population. The advancement in control strategy, battery management system and less costly component utilization will decrease the purchase and operational costs which will attract more people to buy such vehicles.

\subsection{Market share}

According to [291], global sales of EVs have climbed from 1.2 million in 2017 to 1.6 million in 2018 and it has been estimated that it will rise to 2 million in 2019,7 million in 2020, 30 million in 2030 and 100 million in 2050. The share of these vehicles globally is increased from $0.5 \%$ in 2014 to $1.7 \%$ in 2017. In 2017, China has $48 \%$ of market share and Europe has 26\%. In terms of EV sales by

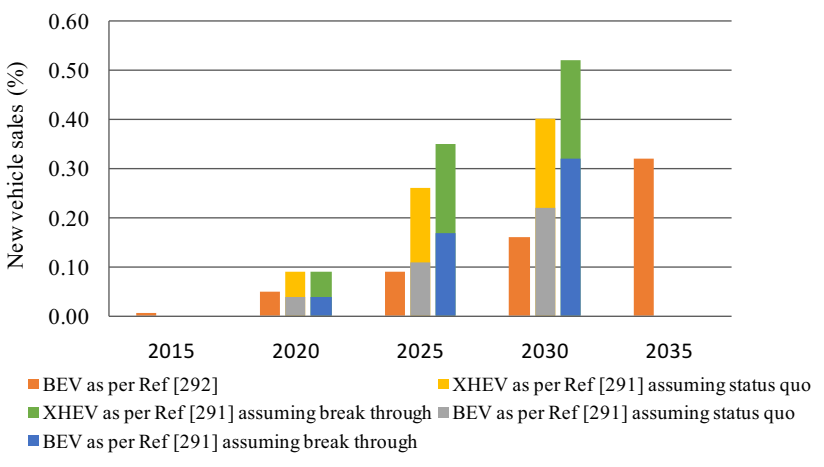

Fig. 7 Medium- and long-term sales of hybrid vehicles

country, China was once again the leader of the pack with over 600,000-unit sales, far ahead of USA which racked up 200,000 .

It is expected that the penetration of EV/PHEVs will be around $35-47 \%$ of the new cars by 2040 . It is observed that agencies have provided different statistics based on the growth rates, and thus, there are no unique data available on the long-term market share of these vehicles. The data on BEVs and XHEVs (including full HEVs and PHEVs) are taken from McKinsey [291] and Morgan Stanley \& Co. [292] as they are the player in the vehicle domain statistics and the same is shown in Fig. 7. In [292], data are given for BEVs and XHEV for China, USA and Europe for status quo assumption and with breakthrough assumption till 2030, whereas in [293], the worldwide total data are given for BEVs till 2035. It can easily be inferred that the share of green vehicles will increase over the coming years.

The six European countries, i.e., Germany, France, Norway, Netherlands, UK and Sweden, are expected to share more than $67 \%$ of the total BEV market in the year 2020, whereas only four countries (Germany, France, Italy and UK) are expected to share more than $52 \%$ of the total market share of PHEVs [294]. According to Pike Research forecast, almost 1.8 million of BEVs, 1.2 million of PHEVs and 1.7 million of HEVs are expected on Europe's roadways by 2020 [295-297].

\subsection{Costs involved}

Ever since its inception, the cost of HEVs has always been much higher than its traditional counterparts in the same segment. Studying just its model price would be misleading, so it is necessary to realize the various costs, such as maintenance, repair, depreciation and fuel to get the complete picture. Comparisons between various costs involved in vehicle are as follows:

1. Fuel costs The main difference between EVs and ICVs is their fuel source, ICVs run on gasoline, while EVs run on electricity. According to a study of the 
University of Michigan's Transportation Research Institute, the operating cost of EV is less than half of gas-powered cars. The average operating cost of an $\mathrm{EV}$ is $\$ 485 /$ year as against $\$ 1,117$ for gasolinepowered vehicles in the USA. This figure is subject to the rates of gas and electricity.

2. Purchase cost The base price for an EV in general is seen to be higher in comparison with traditional alternatives. Higher costs can be attributed to increased complexity and number of components in an HEV and specialized parts.

3. Maintenance costs In ICVs, vehicle maintenance costs can be very high due to engine maintenance which is a huge money sink, which further increases as the car ages. Changing the engine oil, coolant, transmission fluid and belts can add up in value over time. Since an $\mathrm{EV}$ does not have these parts, such repair costs are averted. The universal vehicle expenses, i.e., tire and brake changes, insurance and structural repair, are part of owning any vehicle. EVs are also not free of expenses. The highest maintenance cost associated with EVs is due to its battery which is unlike normal batteries. EV has large complex rechargeable batteries, which are quite resistant to any defect but degrade with time, and their replacement is quite expensive.

4. Depreciation cost HEVs have seen a higher rate of depreciation compared to ICVs. Deprecation is judged by its resale ability. One possible reason for the higher depreciation cost could be linked to the rapid advancement in HEV technology. An HEV which was once state of the art could become much inferior within a short period due to the recent stress in research in this field.

5. Electric car rebates and incentives A great reason which attracts consumers to go for EVs is the country and state incentives available in the form of various subsidies and policies. These rebates help offset the typically higher cost of an electric car to make "going electric" more financially feasible [298].

EVs are not for every lifestyle, but when compared to the myriad costs surrounding ICV purchase and maintenance, choosing an EV can be an intelligent fiscal decision. Table 8 summarizes total costs of ownership (TCO) of the selected drivetrain architectures. They are derived assuming the average German holding period of 4 years and an average yearly driving distance of $10,000 \mathrm{~km}$. The cost breakdown for a midsized conventional car with a gasoline engine versus different hybrid architectures, a full battery electric car and a fuel cell vehicle is summarized in Table 8. The TCO assessment covers all types of expenses accruing for a vehicle owner including one-time cost (e.g., purchase price, expected resale value) as well as operating cost (e.g., fuel/energy, vehicle tax, general/exhaust inspection, maintenance and repair) [299, 300]. It can immediately be inferred that HEVs are economical.

\subsection{Affordability}

While discussing about HEVs, a natural question that arises is affordability. The government of every country is taking interest to search for an alternative method of transportation which is accessible to the public. As such, there is a rapid deployment of well-managed infrastructure to supplement electric technology. Since the production of the batteries has increased, its cost was shaved by approximately $50 \%$ and is expected to be lesser than $\$ 200 / \mathrm{kWh}$ by 2020. Improvement in battery technology will reduce the cost of the hybrid vehicle and make it accessible to more people. It is expected that EVs can be made affordable by 2022 even if the conventional cars improve their fuel efficiency by $3.5 \%$ a year. The analysis uses the US government's projected oil price of $\$ 50-\$ 70$ (£36-£50) a barrel in the 2020s. If the price is $\$ 20$, the tipping point is pushed back between 3 and 9 years. Figure 8 depicts the battery pricings over the next 12 years, and it can be inferred that by 2022, EVs are likely to cost the same as ICE vehicle equivalent.

Consequently, EVs will reduce the revenue from ICE vehicle, but it will compensate via the revenue generated from this new window of opportunity for car manufacturers, for charging infrastructure companies and for battery manufacturers. Solid-state batteries will be the key to the enhancement in battery performance as they are 2.5 times denser than lithium-ion batteries.

The past 6 months have witnessed 10 future plans for launching $\mathrm{EV}$ from varied automakers. Based on these plans it is expected that about 25 million units would be on the road by 2025 . Tesla Gigafactory is currently $35 \%$ operational and aims to produce $50 \mathrm{GWh}$ of batteries in 2018. The EV charging station is a big hindrance which has yet not been focused and needs global attention. Currently, charging stations are present in limited areas where EVs sale is higher.

According to 2018 statistics, the total cost of ownership of a Ford Fusion Hybrid would amount to $\sim \$ 35,606$. This HEV lies comfortably in the midsize market range. In contrast to this, a Honda Accord, which is a traditional vehicle, would cost $\sim \$ 35,709$. By comparing other car models, it is evident that HEVs are now as price competitive as ICE vehicles. When looking into the compact market, it is seen that an HEV would be about $\sim \$ 9,000$ $\$ 10,000$ more expensive. The difference of the pricing in the two segments can be understood due to the higher maintenance and fuel consumption of a midsize IC-driven vehicle compensating for a more expensive battery and 


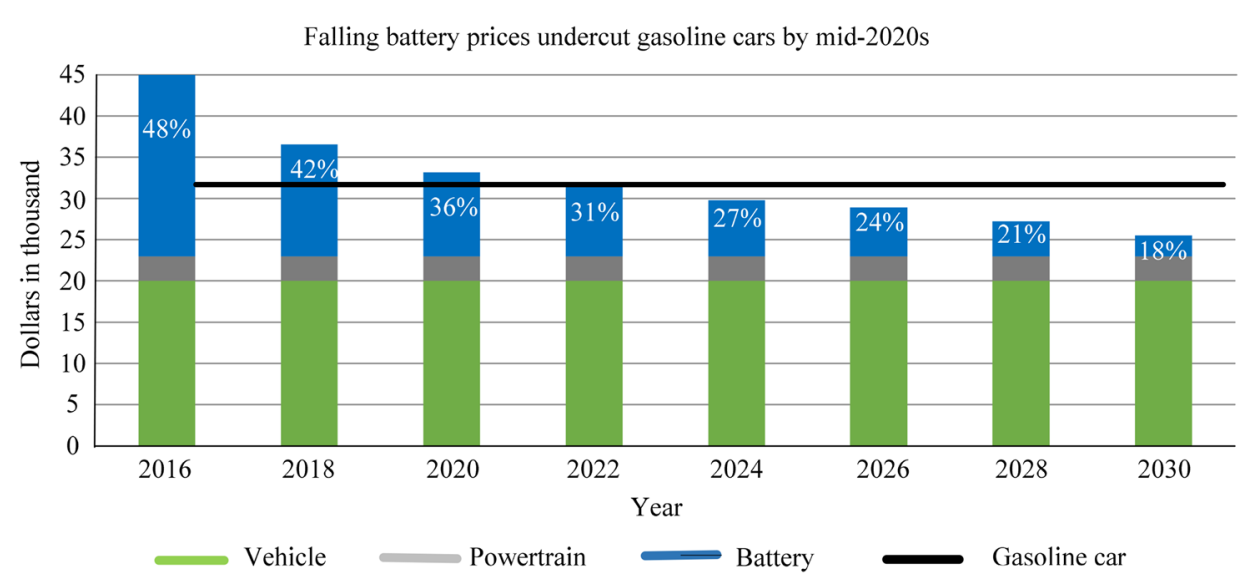

Fig. 8 Price fall status of hybrid vehicles [297]

base price. In a compact vehicle, the fuel consumption is also lower. Apart from that, the depreciation seen in a compact HEV is surprisingly higher which could be due to its lesser demand and product and rapid technology changes in the field. It is evident that HEVs in the midsize market are already price competitive and are affordable choices [301-304].

\section{Conclusion}

HEVs are rapidly emerging as a potential alternative to the existing state of transportation due to their lower petroleum consumption and toxic emission. Strict $\mathrm{CO}_{2}$ emission laws and increased public awareness will propel HEVs to be the future of road transportation. Penetration of PHEVs in the market will change the operations of electric grid substantially, and efforts are being made to provide a two-way communication between the user and the grid. A review of various components of HEVs like architecture, bidirectional converter, ESS, motors and MPPT has been presented, and the findings are summarized at the end of each topic in tabular form.

Based on the literature review, it is found that the complex hybrid architecture will provide greater efficiency, trading off on higher costs and more complex designs. As the inverters are needed to interface the motor engine with ESS, their selection is of prime importance and q-ZSI is found to be a promising candidate.

To extend the battery life, it is suggested to combine UC with battery which will further improve the fuel efficiency and performance during varying ambient conditions.

Based on the study carried out, it is observed that there is a growing interest in developing advanced traction motors for hybrid vehicles and many traction motors are available in the market. However, considering the trade-off based on performance, robustness, reliability and cost, the choice is often between induction motor and permanent magnet AC motor.

PVHEVs are still in infant stage and being explored to minimize gasoline consumption and maximize the usage of renewable energy. Various MPPT algorithms tuned with artificial intelligence techniques like FL, ANN and PSO are also being explored for PVHEV applications.

A comparison of various existing hybrid vehicles is provided in Table 9 which will serve as a guide to choose the best option. This paper provides all necessary information regarding the above-mentioned components and may be considered as a comprehensive document for the researchers and academicians who wish to carry out research in the field of hybrid vehicles.

Open Access This article is distributed under the terms of the Creative Commons Attribution 4.0 International License (http:// creativecommons.org/licenses/by/4.0/), which permits unrestricted use, distribution, and reproduction in any medium, provided you give appropriate credit to the original author(s) and the source, provide a link to the Creative Commons license, and indicate if changes were made.

\section{References}

1. Badin F, Scordia J, Trigui R et al (2006) Hybrid electric vehicles energy consumption decrease according to drive train architecture, energy management and vehicle use. IET Hybrid Veh Conf 2006:213-223. https://doi.org/10.1049/cp:20060610

2. Sandy Thomas CE (2009) Transportation options in a carbonconstrained world: hybrids, plug-in hybrids, biofuels, fuel cell electric vehicles, and battery electric vehicles. Int J Hydrogen Energy 34:9279-9296. https://doi.org/10.1016/j.ijhydene.2009. 09.058 
3. Panday A, Bansal HO (2014) A review of optimal energy management strategies for hybrid electric vehicle. Int J Veh Technol 160510:1-19. https://doi.org/10.1155/2014/160510

4. Eshani M, Gao Y, Gay S, Emadi A (2010) Modern electric, hybrid electric and fuel cell vehicles, 2nd edn. CRC Press, Boca Raton

5. Rokadiya S, Bandivadekar A (2016) Hybrid and electric vehicles in India - current scenario and market incentives. Int Counc Clean Transp. http://www.fame-india.gov.in/ViewNotificationDetails. aspx?RowId=5. 3 March 2015

6. Jennings PA, Jones RP, McGordon A (2010) Generalised fuzzylogic-based power management strategy for various hybrid electric vehicle powertrain architectures. UKACC Int Conf Control 2010:197-202. https://doi.org/10.1049/ic.2010.0280

7. NPTEL Module 3 Architecture of Hybrid and Electric Vehicles Lecture 5: Basic Architecture of Hybrid Drive Trains and Analysis of Series Drive Train. Introd to Hybrid Electr Veh Modul, pp 1-43

8. Chan CC, Bouscayrol A, Chen K (2010) Electric, hybrid, and fuel-cell vehicles: architectures and modeling. IEEE Trans Veh Technol 59:589-598. https://doi.org/10.1109/TVT.2009. 2033605

9. Babu A, Ashok S (2015) Parallel mild hybrid equivalent to the Tata Safari. In: Proc IEEE int conf technol adv power energy (TAP energy), pp 506-510. https://doi.org/10.1109/tapenergy. 2015.7229671

10. Gao Yimin, Ehsani M, Miller J (2005) Hybrid electric vehicle: overview and state of the art. Proc IEEE Int Symp Ind Electron (ISIE) 2005:307-316. https://doi.org/10.1109/ISIE.2005. 1528929

11. Shen C, Shan P, Gao T (2011) A comprehensive overview of hybrid electric vehicles. Int J Veh Technol. https://doi.org/10. 1155/2011/571683

12. Omar N, Fleurbaey K, Kurtulus C et al (2013) SuperLIB project - analysis of the performances of the hybrid Lithium HE-HP architecture for plug-in hybrid electric vehicles. World Electr Veh J 6:259-268. https://doi.org/10.1109/EVS.2013.6914717

13. Li X, Williamson SS (2008) Efficiency and suitability analyses of varied drive train architectures for plug-in hybrid electric vehicle (PHEV) applications. IEEE Veh Power Propuls Conf VPPC. https://doi.org/10.1109/vppc.2008.4677773

14. Ceraolo M, di Donato A, Franceschi G (2008) A general approach to energy optimization of hybrid electric vehicles. IEEE Trans Veh Technol 57:1433-1441. https://doi.org/10. 1109/TVT.2007.909268

15. Meisel J, Shabbir W, Evangelou SA (2013) Evaluation of the through-the-road architecture for plug-in hybrid electric vehicle powertrains. IEEE Int Electr Veh Conf IEVC. https://doi.org/10. 1109/ievc.2013.6681143

16. Zulkifli SA, Mohd S, Saad N (2015) Split-parallel through-theroad hybrid electric vehicle: operation, power flow and control modes. In: IEEE transportation electrification conference and expo (ITEC) Dearborn MI 2015:1-7. https://doi.org/10.1109/ itec.2015.7165774

17. Zulkifli SA, Mohd S, Saad N, Aziz ARA (2015) Operation, power flow, system architecture and control challenges of splitparallel through-the-road hybrid electric vehicle. In: 2015 10th Asian Control Conf Emerg Control Tech a Sustain World (ASCC). https://doi.org/10.1109/ascc.2015.7244637

18. Miller JM (2006) Hybrid electric vehicle propulsion system architectures of the e-CVT type. IEEE Trans Power Electron 21:756-767. https://doi.org/10.1016/j.healun.2006.03.007

19. Babu A, Ashok S (2012) Algorithm for selection of motor and vehicle architecture for a plug-in hybrid electric vehicle. In: India conf (INDICON), annu IEEE, vol 1, pp 875-878
20. Taylor DG (2014) Systematic approach to the modeling and control of hybrid electric vehicle powertrains. In: IECON 2014 -40th annual conference of the IEEE Industrial Electronics Society, pp 3060-3065. https://doi.org/10.1109/iecon. 2014.7048946

21. Shen J, Khaligh A (2015) An energy management strategy for an EV with two propulsion machines and a hybrid energy storage system. In: IEEE transp electrif conf expo, ITEC, pp 1-5. https://doi.org/10.1109/itec.2015.7165791

22. Yin $\mathrm{H}$, Zhou W, Li M et al (2016) An adaptive fuzzy logic based energy management strategy on battery/ultracapacitor hybrid electric vehicles. IEEE Trans Transp Electrif 2:300-311. https:// doi.org/10.1109/TTE.2016.2552721

23. Idoumghar L, Fodorean D, Miraoui A (2010) Using hybrid constricted particles swarm and simulated annealing algorithm for electric motor design. In: Dig 14th Bienn IEEE conf electromagn F comput CEFC 2010 68093. https://doi.org/10.1109/ cefc. 2010.5481410

24. EINozahy MS, Salama MMA (2015) Uncertainty-based design of a bilayer distribution system for improved integration of PHEVs and PV arrays. IEEE Trans Sustain Energy 6:659-674. https://doi.org/10.1109/TSTE.2015.2405411

25. Zhang M, Yang Y, Mi CC (2012) Analytical approach for the power management of blended-mode plug-in hybrid electric vehicles. IEEE Trans Veh Technol 61:1554-1566. https://doi. org/10.1109/TVT.2012.2187318

26. Pandey NK, Thimmalapura S, Isac P (2016) Real world challenges in development of alternate propulsion solutions: an Indian perspective. In: IEEE int transp electrif conf ITEC-India. https://doi.org/10.1109/itec-india.2015.7386940

27. Denis N, Dubois MR, Trovao JPF, Desrochers A (2018) Power split strategy optimization of a plug-in parallel hybrid electric vehicle. IEEE Trans Veh Technol 67:315-326. https://doi.org/ 10.1109/TVT.2017.2756049

28. Cheng R, Dong Z (2015) Modeling and simulation of plug-in hybrid electric powertrain system for different vehicular application. In: IEEE Veh power propuls conf VPPC proc. https://doi. org/10.1109/vppc.2015.7352976

29. Butler KL, Ehsani M, Kamath P (1999) A Matlab-based modeling and simulation package for electric and hybrid electric vehicle design. IEEE Trans Veh Technol 48:1770-1778. https:// doi.org/10.1109/25.806769

30. Inokuchi S, Co ME, Inokuchi S (2015) A new versatile high power Intelligent Power Module (IPM) for EV and HEV applications. In: PCIM Asia 2015; international exhibition and conference for power electronics, intelligent motion, renewable energy and energy management, Shanghai, China, pp 1-5

31. Jang M, Agelidis VG (2013) A digitally controlled single-phase buck-boost-inverter using a dual-DSP. IN: IECON Proc (Industrial Electron Conf), pp 187-192. https://doi.org/10.1109/ iecon.2013.6699133

32. Koushki B, Student I, Ghaisari J, Member I (2009) A voltage reference design for three-phase boost inverter. In: IEEE EUROCON St Petersburg, pp 650-654. https://doi.org/10.1109/ eurcon.2009.5167702

33. Safaee A, Yazdani D, Pahlevaninezhad M (2011) Resonant DClink soft-switched DC-AC converters 011 IEEE international electric machines \& drives conference (IEMDC), Niagara Falls, pp 260-264. https://doi.org/10.1109/iemdc.2011.5994856

34. Liwei S, Zijian L, Qianfan Z et al (2007) Research of an energyfed induction motor driving test platform with double inverters for HEV. In: VPPC - Proc IEEE Veh Power Propuls Conf, pp 531-535. https://doi.org/10.1109/vppc.2007.4544181

35. Marcinkowski J (2014) Dual-sided cooling of power semiconductor modules. In: CIM Europe 2014; International exhibition and conference for power electronics, intelligent motion, 
renewable energy and energy management, Nuremberg Germany, pp. 1-7

36. Adachi S, Yoshida S, Miyata H et al (2016) Automotive power module technologies for high speed switching. In: International exhibition and conference for power electronics, intelligent motion, renewable energy and energy management, Nuremberg Germany, pp 1-7

37. Shim H, Kim H, Kwack $Y$ et al (2015) Inverter modeling including non-ideal IGBT characteristics in Hybrid Electric Vehicle for accurate EMI noise prediction. In: IEEE Int Symp Electromagn Compat 2015-Septm, pp 691-695. https://doi.org/ $10.1109 /$ isemc.2015.7256247

38. Lee J, Jang H, Shin S et al (2016) Over temperature protection in power module for hybrid and electric vehicle. In: 016 IEEE transportation electrification conference and expo, Asia-Pacific (ITEC Asia-Pacific), pp 432-435.https://doi.org/10.1109/itecap.2016.7512992

39. Han P, Cheng M, Zhu S, Chen Z (2015) Brushless doubly-fed induction drive for EV/HEV applications. Electrical machines and systems (ICEMS), pp 320-326

40. Dey T, Mukherjee K, Syam P (2016) Dynamic adjustments of the D-Q axes reference voltage limits during flux weakening and MTPA control of an IPMSM drive for an EV application. In: 2nd Int conf control instrumentation, energy commun (CIEC), pp 324-328. https://doi.org/10.1109/ciec.2016.7513821

41. Roche M, Shabbir W, Evangelou S (2016) Voltage control for enhanced power electronic efficiency in series hybrid electric vehicles. IEEE Trans Veh Technol 9545:1-1. https://doi.org/10. 1109/TVT.2016.2599153

42. Gautam AK, Singh SP, Pandey JP, Shukla TN (2016) Performance investigation of permanent magnet synchronous motor (PMSM) drive supplied from hybrid sources. Int Conf Emerg Trends Electr Electron Sustain Energy Syst (ICETEESES) 2016:292-302. https://doi.org/10.1109/ICETEESES.2016. 7581396

43. Winzer P, Doppelbauer M (2016) A hybrid permanent magnet and wound field synchronous machine with displaced reluctance axis capable of symmetric four quadrant operation. In: 2016 18th Eur conf power electron Appl EPE (ECCE Eur). https://doi. org/10.1109/epe.2016.7695296

44. Boxriker M, Kolb J, Doppelbauer M (2016) Expanding the operating range of permanent magnet synchronous motors by using the optimum number of phases. In: 18th Eur conf power electron appl EPE 2016 ECCE Eur. https://doi.org/10.1109/epe. 2016.7695597

45. Senanayake T, Iijima R, Isobe T, Tadano H (2016) Z-source with rectangular wave modulation inverter for Hybrid/Electric vehicles. In: 18th European conference on power electronics and applications (EPE'16 ECCE Europe). IEEE, pp 1-10

46. Ye H, Bilgin B, Emadi A (2012) Reduced-parts three-phase inverters: a comparative study. In: IEEE transp electrif conf expo (ITEC) 2012, pp 8-13. https://doi.org/10.1109/itec.2012. 6243455

47. Wu Z, Su G-J (2008) High-performance permanent magnet machine drive for electric vehicle applications using a current source inverter. In: Ind electron (IECON) 34th annu conf IEEE, pp 2812-2817. https://doi.org/10.1109/iecon.2008.4758404

48. Liaw CM (1990) Modified linear model-following controller for current-source inverter-fed induction motor drives. IEEE Proc D Control Theory Appl 137:49. https://doi.org/10.1049/ip-d.1990. 0005

49. Enjeti PN, Ziogas PD, Lindsay JF (1988) A current source PWM inverter with instantaneous current control capability (AC motors). In: Conference record of the IEEE industry applications society annual meeting, IEEE, pp 927-933
50. Wu B, Slemon GR, Dewan SB (1991) PWM-CSI induction motor drive with phase angle control. IEEE Trans Ind Appl 27:970-976. https://doi.org/10.1109/28.90355

51. Bassi E, Benzi FP, Bolognani S, Buja GS (1992) A field orientation scheme for current-fed induction motor drives based on the torque angle closed-loop control. IEEE Trans Ind Appl 28:1038-1044. https://doi.org/10.1109/28.158827

52. Ando T, Nakazato M (1992) Development of a high-speed elevator controlled by current source inverter system with sinusoidal input and output. IEEE Trans Ind Appl 28:893-899. https://doi.org/10.1109/28.148457

53. Nonaka S, Neba Y (1992) Current regulated PWM-CSI induction motor drive system without a speed sensor. In: Conf RecIAS annu meet IEEE ind appl soc 1992-Janua, pp 347-354. https://doi.org/10.1109/ias.1992.244274

54. Espinoza JR, Joós G (1998) A Current-source-inverter-fed induction motor drive system with reduced losses. IEEE Trans Ind Appl 34:796-805. https://doi.org/10.1109/28.703977

55. Lei Q, Peng FZ (2014) Space vector pulsewidth amplitude modulation for a buck-boost voltage/current source inverter. IEEE Trans Power Electron 29:266-274. https://doi.org/10. 1109/TPEL.2012.2225847

56. Liu S, Hameyer K (2013) A current source inverter for battery electric vehicles. In: 15 th European conference on power electronics and applications (EPE). IEEE, pp 1-10

57. Von Malottki S, Scharfenstein D, Hameyer K (2014) A method to switch off an IPMSM by a Current-Source-Inverter in the event of a malfunction in a Battery Electric Vehicle. In: 16th Eur Conf Power Electron Appl EPE-ECCE Eur, pp 1-9. https://doi. org/10.1109/epe.2014.6910966

58. Liu JLJ, Wen HWH, Zhang XZX (2008) Analysis of the VSI with small DC-link capacitor for Electric Vehicles. In: Int conf electr mach syst, pp 1401-1405

59. Salmasi FR, Najafabadi TA, Maralani PJ (2010) An adaptive flux observer with online estimation of dc-link voltage and rotor resistance for VSI-Based induction motors. IEEE Trans Power Electron 25:1310-1319. https://doi.org/10.1109/TPEL.2009. 2038268

60. Feng G, Lai C (2016) Current injection based On line parameter and VSI nonlinearity estimation for PMSM drives using current and voltage DC components 7782: 1-9. https://doi.org/10.1109/ tte.2016.2538180

61. Badodkar DN (2018) Transient analysis of three-phase highpower voltage source inverter with nonlinearities. IEEE Trans Power Electron 33(4):3672-3680 10.1109/tpel.2017.2712065

62. Bucher A, Schmidt R, Werner R et al (2016) Design of a full $\mathrm{SiC}$ voltage source inverter for electric vehicle applications siemens AG, eCar Powertrain Systems Keywords. In: 18th Eur Conf Power Electron Appl 1-10. https://doi.org/10.1109/epe. 2016.7695414

63. Yao F, Geng L, Janabi A, Wang B (2017) Impact of modulation schemes on DC-link capacitor of VSI in HEV applications. In: IEEE int electr mach drives conf IEMDC. https://doi.org/10. 1109/iemdc.2017.8002186

64. Ellabban O, Mierlo J Van, Lataire P, Elsene B- (2009) Comparison between different PWM control methods for different Zsource inverter topologies keywords review of PWM control methods for ZSI simple boost control modified space vector PWM (MSVPWM) control. In: 13th Eur conf power electron appl

65. Moon A (2016) Analysis of boost converter and interleaved converter for permanent magnet synchronous motor of hybrid electrical vehicle. In: International conference on electrical, electronics, and optimization techniques (ICEEOT), pp 4298-4303. https://doi.org/10.1109/iceeot.2016.7755530 
66. Senanayake $\mathrm{T}$, Iijima $\mathrm{R}$, Isobe $\mathrm{T}$, Tadano $\mathrm{H}$ Z-source with rectangular wave modulation inverter for hybrid/electric vehicles. Department of Pure and Applied Sciences, Division of Applied Physics Keywords Motivation Rectangular wave driving with conventional ZSI, pp 1-10

67. Cao D, Lei Q, Peng FZ (2013) Development of high efficiency current-fed quasi-Z-source inverter for HEV motor drive. In: Conf proc-IEEE appl power electron conf expo (APEC), pp 157-164. https://doi.org/10.1109/apec.2013.6520201

68. Charboneau BC, Boroyevich D, Wang F et al (2005) Doublesided liquid cooling for power semiconductor devices using embedded power technology. IEEE Trans Ind Appl 44(5):1645-1655. https://doi.org/10.1109/TIA.2008.2002270

69. Xu Z, Xu F, Jiang D et al (2013) A high temperature traction inverter with reduced cooling and improved efficiency for HEV applications. In: IEEE energy convers congr expo (ECCE), pp 2786-2792. https://doi.org/10.1109/ecce.2013.6647062

70. Su M, Chen C, Sharma S, Kikuchi J (2015) Performance and cost considerations for SiC-based HEV traction inverter systems. In: 3rd IEEE work wide bandgap power devices appl, pp 347-350. https://doi.org/10.1109/wipda.2015.7369032

71. Jin L, Norrga S, Zhang H, Wallmark O (2016) Evaluation of a multiphase drive system in EV and HEV applications. In: Proc IEEE int electr mach drives conf (IEMDC), pp 941-945. https:// doi.org/10.1109/iemdc.2015.7409174

72. Inokuchi S, Saito S, Izuka A (2016) A new high capacity compact power modules for high power EV/HEV inverters. In: IEEE applied power electronics conference and exposition (APEC), pp 468-471. https://doi.org/10.1109/apec.2016. 7467913

73. Lu X, Qian W, Cao D et al (2011) A carrier modulation method for minimizing the dc link capacitor current ripple of the HEV DC-DC converter and inverter systems. In: Conf proc IEEE appl power electron conf expo (APEC), pp 800-807. https://doi.org/ 10.1109/apec.2011.5744687

74. Lu X, Peng FZ (2012) Theoretical analysis of DC link capacitor current ripple reduction in the HEV DC-DC converter and inverter system using a carrier modulation method. In: IEEE energy convers congr expo (ECCE), pp 2833-2839. https://doi. org/10.1109/ecce.2012.6342376

75. Ye H, Emadi A (2014) An interleaving scheme to reduce DClink current harmonics of dual traction inverters in hybrid electric vehicles. In: Conf proc IEEE appl power electron conf expo (APEC), pp 3205-3211. https://doi.org/10.1109/apec.2014. 6803764

76. Norrga S, Jin L, Wallmark $\mathrm{O}$ et al (2013) A novel inverter topology for compact $\mathrm{EV}$ and $\mathrm{HEV}$ drive systems. In: Proc industrial electron conf (IECON), pp 6590-6595. https://doi.org/ 10.1109/iecon.2013.6700222

77. Kim JH, Kang HS, Lee BK, Hur J (2008) Cost effective PAM inverter for $42 \mathrm{~V}$ hybrid electric vehicles (HEV). In: IEEE veh power propuls conf VPPC, pp 1-6. https://doi.org/10.1109/vppc. 2008.4677605

78. Renken F, Ehbauer G, Karrer V et al (2007) Reliability of high temperature inverters for HEV. In: Fourth power convers conf PCC-NAGOYA conf proc, pp 563-568. https://doi.org/10.1109/ pccon.2007.373022

79. Akbarian H, Pillay P, Lopes L (2015) Design of a power electronic emulator for parallel operation of renewable energy resources in microgrids, pp 1532-1537. https://doi.org/10.1109/ iemdc.2015.7409266

80. Nair VV, Pathiyil P (2016) High dynamic HIL model for complete software testing solution of HEV/EV. In: IEEE int transp electrif conf (ITEC) India 2015, pp 1-7. https://doi.org/ 10.1109/itec-india.2015.7386869
81. Cai AQ, Siek L (2017) A 2-kW, 95\% efficiency inductive power transfer system using gallium nitride gate injection transistors. IEEE J Emerg Sel Top Power Electron 5:458-468. https://doi. org/10.1109/JESTPE.2016.2632743

82. Mohamed AAS, Berzoy A, Mohammed OA (2017) Experimental validation of comprehensive steady-state analytical model of bidirectional wpt system in EVs applications. IEEE Trans Veh Technol 66:5584-5594. https://doi.org/10.1109/TVT. 2016.2634159

83. Xu, L, Zhao, DA, Zhang, C, Ge et al (2012) Research on fault analysis and fault-tolerant control of valve electric actuator system based on SRM. In: Fifth international symposium on computational intelligence and design, pp 284-289. https://doi. org/10.1109/iscid.2012.248

84. Yang S, Peng FZ, Lei Q et al (2011) Current-fed quasi-z-source inverter with voltage buck-boost and regeneration capability. IEEE Trans Ind Appl 47:882-892. https://doi.org/10.1109/TIA. 2010.2102995

85. Xu H, Peng FZ, Chen L, Wen X (2008) Analysis and design of bi-directional Z-source inverter for electrical vehicles. In: Conf proc-IEEE appl power electron conf expo APEC, pp 1252-1257. https://doi.org/10.1109/apec.2008.4522883

86. Ding X, Qian Z, Yang S et al. (2007) A new adjustable-speed drives (ASD) system based on high-performance Z-source inverter. In: IEEE industry applications annual meeting, New Orleans, 2327-2332. https://doi.org/10.1109/07ias.2007.351

87. Li X, Williamson SS (2008) Efficiency analysis of hybrid electric vehicle (HEV) traction motor-inverter drive for varied driving load demands. In: Conf proc IEEE appl power electron conf expo (APEC), pp 280-285. https://doi.org/10.1109/apec. 2008.4522734

88. Khaleghi H, Yazdian Varjani A, Mohamadian M (2014) A new bidirectional zeta DC/DC converter. In: PEDSTC 2014-5th annu int power electron drive syst technol conf, pp 131-136. https://doi.org/10.1109/pedstc.2014.6799358

89. Lei Q, Cao D, Peng FZ (2014) Novel loss and harmonic minimized vector modulation for a current-fed quasi-Z-source inverter in HEV motor drive application. IEEE Trans Power Electron 29:1344-1357. https://doi.org/10.1109/TPEL.2013. 2260173

90. Lai Y, Lee W, Lin Y, Tsai J (2014) Integrated inverter/converter circuit and control technique of motor drives with dual-mode control for EV/HEV applications. IEEE Trans Power Electron 29:1358-1365

91. George S, Chacko RV., KS (2014) Modelling and simulation of Electric Vehicle Power train in SEQUEL. In: IEEE international conference on power electronics, drives and energy system. https://doi.org/10.1109/PEDES.2014.7042149

92. Kikuchi J (2015) Stability modeling of HEV/ev electric drives as a small-scale distributed power system. In: IEEE applied power electronics conference and exposition (APEC), pp 2664-2671. https://doi.org/10.1109/apec.2015.7104727

93. Grassmann A, Geitner O, Hable W et al. (2015) Double sided cooled module concept for high power density in HEV applications. In: Proceedings of PCIM Europe 2015; international exhibition and conference for power electronics, intelligent motion, renewable energy and energy management, Nuremberg, Germany, pp 1-7

94. Marcinkowski J, Kempitiya A, Prabhala VA et al (2015) Dualsided cooling for automotive inverters-practical implementation with power module heat sink assembly. In: Proceedings of PCIM Europe; international exhibition and conference for power electronics, intelligent motion, renewable energy and energy management, pp 19-21 
95. Chau KT, Wong YS, Chan CC (1999) An overview of energy sources for electric vehicles. Energy Convers Manag 40:1021-1039. https://doi.org/10.1016/S0196-8904(99)00021-7

96. Khaligh A, Li Z (2010) Battery, ultracapacitor, fuel cell, and hybrid energy storage systems for electric, hybrid electric, fuel cell, and plug-in hybrid electric vehicles: state of the art. IEEE Trans Veh Technol 59:2806-2814. https://doi.org/10.1109/TVT. 2010.2047877

97. Lam LT, Louey R (2006) Development of ultra-battery for hybrid-electric vehicle applications. J Power Sources 158:1140-1148. https://doi.org/10.1016/j.jpowsour.2006.03.022

98. Kuperman A, Aharon I, Kara A, Malki S (2011) A frequency domain approach to analyzing passive battery-ultracapacitor hybrids supplying periodic pulsed current loads. Energy Convers Manag 52:3433-3438. https://doi.org/10.1016/j.enconman.2011. 07.013

99. Ashtiani C, Wright R, Hunt G (2006) Ultracapacitors for automotive applications. J Power Sources 154:561-566. https://doi. org/10.1016/j.jpowsour.2005.10.082

100. Djellad A, Logerais PO, Omeiri A et al (2014) Optimization of the energy transfer in a system combining photovoltaic source to ultracapacitors. Int J Hydrogen Energy 39:15169-15177. https:// doi.org/10.1016/j.ijhydene.2014.03.144

101. Burke A (2000) Ultracapacitor; why, and where is the technology. J Power Sources 91:37-50

102. Solero L, Lidozzi A, Serrao V et al (2011) Ultracapacitors for fuel saving in small size hybrid vehicles. J Power Sources 196:587-595. https://doi.org/10.1016/j.jpowsour.2009.07.041

103. Hredzak B, Agelidis VG, Jang M (2014) A model predictive control system for a hybrid battery-ultracapacitor power source. IEEE Trans Power Electron 29:1469-1479. https://doi.org/10. 1109/TPEL.2013.2262003

104. Hochgraf CG, Basco JK, Bohn TP, Bloom I (2012) Effect of ultracapacitor-modified PHEV protocol on performance degradation in lithium-ion cells. J Power Sources 246:1-5. https://doi. org/10.1016/j.jpowsour.2012.09.038

105. Zhang L, Hu X, Wang Z et al (2015) Experimental impedance investigation of an ultracapacitor at different conditions for electric vehicle applications. J Power Sources 287:129-138. https://doi.org/10.1016/j.jpowsour.2015.04.043

106. Stienecker AW, Stuart T, Ashtiani C (2006) An ultracapacitor circuit for reducing sulfation in lead acid batteries for mild hybrid electric vehicles. 156:755-762. https://doi.org/10.1016/j. jpowsour.2005.06.014

107. Hannana MA et al (2017) Review of energy storage systems for electric vehicle applications: issues and challenges. Renew Sustain Energy Rev 69:771-789

108. Kuperman A, Aharon I (2011) Battery-ultracapacitor hybrids for pulsed current loads: a review. Renew Sustain Energy Rev 15:981-992. https://doi.org/10.1016/j.rser.2010.11.010

109. Rambaldi L, Bocci E, Orecchini F (2011) Preliminary experimental evaluation of a four wheel motors, batteries plus ultracapacitors and series hybrid powertrain. Appl Energy 88:442-448. https://doi.org/10.1016/j.apenergy.2010.08.008

110. Burke A, Miller M (2011) The power capability of ultracapacitors and lithium batteries for electric and hybrid vehicle applications. J Power Sources 196:514-522. https://doi.org/10. 1016/j.jpowsour.2010.06.092

111. Pay S, Baghzouz Y (2003) Effectiveness of battery-supercapacitor combination in electric vehicles. In: 2003 IEEE Bol powertech-conf proc vol, 3, pp 728-733. https://doi.org/10. $1109 /$ ptc. 2003.1304472

112. Shen J, Khaligh A (2016) Predictive control of a battery/ultracapacitor hybrid energy storage system in electric vehicles. IEEE Transp Electrif Conf Expo, ITEC 2016:1-6. https://doi. org/10.1109/ITEC.2016.7520297
113. Lajnef W, Vinassa JM, Briat O, Woirgard E (2005) Specification and use of pulsed current profiles for ultracapacitors power cycling. Microelectron Reliab 45:1746-1749. https://doi.org/10. 1016/j.microrel.2005.07.102

114. McDonough M (2015) Integration of inductively coupled power transfer and hybrid energy storage system: a multiport power electronics interface for battery-powered electric vehicles. IEEE Trans Power Electron 30:6423-6433. https://doi.org/10.1109/ TPEL.2015.2422300

115. Marzougui H, Amari M, Kadri A, Bacha F (2016) Science Direct Energy management of fuel cell/battery/ultracapacitor in electrical hybrid vehicle. Int J Hydrogen Energy 2:1-13. https:// doi.org/10.1016/j.ijhydene.2016.09.190

116. Panday A, Bansal HO (2013) Temperature dependent circuitbased modeling of high power Li-ion battery for plug-in hybrid electrical vehicles. In: Int conf adv technol eng ICATE 2013. https://doi.org/10.1109/icadte.2013.6524737

117. Wang C, He H, Zhang Y, Mu H (2017) A comparative study on the applicability of ultracapacitor models for electric vehicles under different temperatures. Appl Energy 196:268-278. https:// doi.org/10.1016/j.apenergy.2017.03.060

118. Capasso C, Veneri O (2017) Integration between Super-capacitors and ZEBRA batteries as high performance hybrid storage system for electric vehicles. Energy Procedia 105:2539-2544. https://doi.org/10.1016/j.egypro.2017.03.727

119. Bubna P, Advani SG, Prasad AK (2012) Integration of batteries with ultracapacitors for a fuel cell hybrid transit bus. J Power Sources 199:360-366. https://doi.org/10.1016/j.jpowsour.2011. 09.097

120. Kagiri C, Xia X (2017) Optimal control of a hybrid battery/supercapacitor storage for neighborhood electric vehicles. Energy Procedia 105:2145-2150. https://doi.org/10.1016/j. egypro.2017.03.605

121. Dhaouadi R, Hori Y, Xiaoliang H (2014) Robust control of an ultracapacitor-based hybrid energy storage system for electric vehicles. In: IEEE 13th Int work adv motion control, pp 161-166. https://doi.org/10.1109/amc.2014.6823275

122. Michalczuk M, Grzesiak LM, Ufnalski B (2015) Experimental parameter identification of battery-ultracapacitor energy storage system. In: IEEE int symp ind electron-Septe, pp 1260-1265. https://doi.org/10.1109/isie.2015.7281653

123. Zhang S, Xiong R, Sun F (2015) Model predictive control for power management in a plug-in hybrid electric vehicle with a hybrid energy storage system. Appl Energy 185:1654-1662. https://doi.org/10.1016/j.apenergy.2015.12.035

124. Ma C, Chow M-Y, Razik H, Khaligh A (2016) Guest editorial special section on networked energy systems: architectures, communication, and management. IEEE Trans Ind Inform 12:1896-1899. https://doi.org/10.1109/TII.2016.2606250

125. Lei Z, Zhenpo W, Xiaosong H, Dorrell DG (2014) Residual capacity estimation for ultracapacitors in electric vehicles using artificial neural network. IFAC Proc 47:3899-3904. https://doi. org/10.3182/20140824-6-ZA-1003.00657

126. Li Q, Chen W, Li Y et al. (2012) Electrical Power and Energy Systems Energy management strategy for fuel cell/battery/ultracapacitor hybrid vehicle based on fuzzy logic 43:514-525. https://doi.org/10.1016/j.ijepes.2012.06.026

127. Jin F, Wang M, Hu C (2016) A fuzzy logic based power management strategy for hybrid energy storage system in hybrid electric vehicles considering battery degradation, pp 1-7. https:// doi.org/10.1109/itec.2016.7520207

128. Liu J, Yan Q, Qu X et al (2014) Explicit model predictive control of bidirectional DC/DC converter for ultracapacitors energy storage unit applied to light rail vehicle. IFAC Proc 47:10293-10298. https://doi.org/10.3182/20140824-6-ZA-1003. 01216 
129. Pavkovi D, Lobrovi M, Hrgeti M, Komljenovi A (2014) A design of DC bus control system for EVs based on battery/ ultracapacitor hybrid energy storage. IEEE Int Elect Veh Conf. 99:99-100. https://doi.org/10.1109/ievc.2014.7056088

130. Zhao C, Yin H, Fu M (2014) Analysis, control, and wireless charging of energy systems using ultracapacitors. In: 2014 IEEE international electric vehicle conference (IEVC), Florence 2014, pp 1-8. https://doi.org/10.1109/ievc.2014.7056130

131. Wang B, Xu J, Cao B, Zhou X (2015) A novel multimode hybrid energy storage system and its energy management strategy for electric vehicles. J Power Sources 281:432-443. https://doi.org/ 10.1016/j.jpowsour.2015.02.012

132. Wang Y, Liu C, Pan R, Chen Z (2017) Modeling and state-ofcharge prediction of lithium-ion battery and ultracapacitor hybrids with a co-estimator. Energy 121:739-750. https://doi. org/10.1016/j.energy.2017.01.044

133. Snoussi J, Elghali S Ben, Outbib R, Mimouni MF (2015) Model predictive control for hybrid battery/ultracapacitor power supply used in vehicular applications. In: 16th international conference on sciences and techniques of automatic control and computer engineering (STA), pp 193-200. https://doi.org/10.1109/STA. 2015.7505200

134. Li J, Fu Z, Jin X (2017) Rule Based energy management strategy for a battery/ultra-capacitor hybrid energy storage system optimized by pseudospectral method. Energy Procedia 105:2705-2711. https://doi.org/10.1016/j.egypro.2017.03.920

135. Yavasoglu HA, Shi C, Member S, Gokce K (2017) Energy storage systems for EVs with two propulsion machines. In: Transportation electrification conference and expo (ITEC) IEEE, pp 696-700

136. Kimura A, Abe T, Sasaki S (1999) Drive force control of a parallel-series hybrid system. JSAE Rev 20:337-341. https://doi. org/10.1016/S0389-4304(99)00017-X

137. Yavasoglu HA, Member S, Shen J, Member S (2015) Power split control strategy for an EV powertrain with two propulsion machines. IEEE Trans Transp Electrif 1:382-390. https://doi. org/10.1109/TTE.2015.2504406

138. Yin H, Zhou W, Li M et al (2016) An adaptive fuzzy logic based energy management strategy on battery/ultracapacitor hybrid electric vehicles. IEEE Trans Transp Electr 555:1-12

139. Chemali E, McCurlie L, Howey B et al. (2015) Minimizing battery wear in a battery-ultracapacitor hybrid energy storage system using a linear quadratic regulator. In: IEEE conf indus elect soc, pp 3265-3270

140. Ko Y, Lee J, Lee H (2015) A supervisory control algorithm for a series hybrid vehicle with multiple energy sources. IEEE Trans Veh Technol 64:4942-4953. https://doi.org/10.1109/TVT.2015. 2445872

141. Koushki B, Safaee A, Jain P, Bakhshai A (2014) Review and comparison of bi-directional AC-DC converters with V2G capability for on-board EV and HEV.In: IEEE transp electrif conf expo, pp 1-6. https://doi.org/10.1109/itec.2014.6861779

142. Mane S, Jagtap P, Kazi F, Singh NM (2016) Model predictive control of complex switched mode FC-UC hybrid structure. In: Indian Control Conf (ICC) 2016-proc, pp 66-71. https://doi. org/10.1109/indiancc.2016.7441107

143. Thounthong P, Raël S, Davat B (2009) Energy management of fuel cell/battery/supercapacitor hybrid power source for vehicle applications. J Power Sour 193:376-385. https://doi.org/10. 1016/j.jpowsour.2008.12.120

144. Pitorac C (2016) Using Li-Ion accumulators as traction batteries in the automotive industry. Cost reduction using ultra-capacitors. In: 13th int conf dev appl syst (DAS) conf proc, pp 212-218. https://doi.org/10.1109/daas.2016.7492575

145. Mirzaei A, Jusoh A, Salam Z et al (2011) Analysis and design of a high efficiency bidirectional DC-DC converter for battery and ultracapacitor applications. Simul Model Pract Theory 19:1651-1667. https://doi.org/10.1016/j.simpat.2011.04.007

146. Al-Sheikh H, Bennouna O, Hoblos G, Moubayed N (2014) Power electronics interface configurations for hybrid energy storage in hybrid electric vehicles. In: 17th IEEE mediterr electrotech conf (MELECON), pp 122-126. https://doi.org/10. 1109/melcon.2014.6820518

147. Choi M-E, Kim S-W, Seo S-W (2012) Energy management optimization in a battery/supercapacitor hybrid energy storage system. IEEE Trans Smart Grid 3:463-472. https://doi.org/10. 1109/TSG.2011.2164816

148. Gurkaynak Y, Khaligh A (2009) Control and power management of a grid connected residential photovoltaic system with plug-in hybrid electric vehicle (PHEV) Load. In: 2009 Twentyfourth annu IEEE appl power electron conf expo, pp 2086-2091. https://doi.org/10.1109/apec.2009.4802962

149. Sarkar T, Sharma M (2014) A generalized approach to design the electrical power system of a solar electric vehicle. IN: IEEE students' conference on electrical, electronics and computer science, pp 1-6

150. Asensio M, Magallán G, De Angelo C (2016) Experimental evaluation of different semi-active configurations for batteryultracapacitor hybrid energy storage system (HESS). In: 16th work inf process control RPIC 2015. https://doi.org/10.1109/ rpic.2015.7497176

151. Groen BC (2011) Investigation of DC motors for electric and hybrid electric motor vehicle applications using an infinitely variable transmission. Brigham Young University, Provo.: https://scholarsarchive.byu.edu/etd. Accessed 15 Feb 2018

152. Akar F, Tavlasoglu Y, Ugur E et al. (2015) A Bidirectional nonisolated multi input DC-DC converter for hybrid energy storage systems in electric vehicles. In: IEEE Trans Veh Technol, p 1. https://doi.org/10.1109/tvt.2015.2500683

153. Fathabadi $H$ (2018) Utilizing solar and wind energy in plug-in hybrid electric vehicles. Energy Convers Manag 156:317-328. https://doi.org/10.1016/j.enconman.2017.11.015

154. Sivaprasad A, Joseph J, Kumaravel S, Ashok S (2015) Design and analysis of a dual input DC-DC converter for hybrid electric vehicle. In: IEEE international conference on signal processing, informatics, communication and energy systems (SPICES). https://doi.org/10.1109/spices.2015.7091466

155. Farzanehfard H, Beyragh DS, Adib E (2008) A bidirectional soft switched ultracapacitor interface circuit for hybrid electric vehicles. Energy Convers Manag 49:3578-3584. https://doi.org/ 10.1016/j.enconman.2008.07.004

156. Lopes LAC, Soleimanpour N (2015) Power losses balancing in a three-level NPC converter driving a PMSM in an electric vehicle. IEEE Energy Convers Congr Expo ECCE 2015:1660-1665. https://doi.org/10.1109/ECCE.2015.7309894

157. Al-Sheikh H, Bennouna O, Hoblos G, Moubayed N (2014) Modeling, design and fault analysis of bidirectional DC-DC converter for hybrid electric vehicles. In: IEEE int symp ind electron, pp 1689-1695. https://doi.org/10.1109/isie.2014. 6864869

158. Hashernnia N, Asaei B (2008) Comparative study of using different electric. In: 18th international conference on electrical machines Vilamoura, pp 1-5.https://doi.org/10.1109/icelmach. 2008.4800157

159. Ding W, Hu Y, Wu L (2015) Analysis and development of novel three-phase hybrid magnetic paths switched reluctance motors using modular and segmental structures for EV applications. IEEE/ASME Trans Mechatron 20:2437-2451. https://doi.org/ 10.1109/TMECH.2014.2383615

160. Chen H, Yang Z, Cheng H (2015) Average torque control of switched reluctance machine drives for electric vehicles. IET 
Electr Power Appl 9:459-468. https://doi.org/10.1049/iet-epa. 2014.0424

161. Javad M, Babaghorbani B, Ketabi A (2014) Efficiency improvement and torque ripple minimization of Switched Reluctance Motor using FEM and Seeker Optimization Algorithm. Energy Convers Manag 78:237-244. https://doi.org/10. 1016/j.enconman.2013.11.001

162. Uddin W, Member S, Husain T et al (2016) Design methodology of a switched reluctance machine for off-road vehicle applications. IEEE Trans Ind Appl 52:2138-2147

163. Wang S, Zhan Q, Ma Z, Zhou L (2005) Implementation of a $50-\mathrm{kW}$ four-phase switched reluctance motor drive system for hybrid electric vehicle. IEEE Trans Magn 41:501-504. https:// doi.org/10.1109/TMAG.2004.838985

164. Prasad KMA, Unnikrishnan A, Nair U (2016) Fuzzy sliding mode control of a switched reluctance motor. Procedia Technol 25:735-742. https://doi.org/10.1016/j.protcy.2016.08.167

165. Kiyota K, Kakishima T, Sugimoto H, Chiba A (2013) Comparison of the test result and 3D-FEM analysis at the knee point of a $60 \mathrm{~kW}$ SRM for an HEV. IEEE Trans Magn 49:2291-2294. https://doi.org/10.1109/TMAG.2013.2242453

166. Kiyota K, Kakishima T, Chiba A (2014) Comparison of test result and design stage prediction of switched reluctance motor competitive with 60-kW rare-earth PM motor. IEEE Trans Ind Electron 61:5712-5721. https://doi.org/10.1109/TIE.2014. 2304705

167. Faiz J, Moayed-Zadeh K (2005) Design of switched reluctance machine for starter/generator of hybrid electric vehicle. Electr Power Syst Res 75:153-160. https://doi.org/10.1016/j.epsr.2005. 02.004

168. Sezen S, Karakas E, Yilmaz K, Ayaz M (2016) Finite element modeling and control of a high-power SRM for hybrid electric vehicle. Simul Model Pract Theory 62:49-67. https://doi.org/10. 1016/j.simpat.2016.01.006

169. Xiang Z, Member S, Zhu X et al. (2016) Multilevel design optimization and operation of a brushless double mechanical ports flux-switching permanent magnet motor. 0046:6042-6054. https://doi.org/10.1109/tie.2016.2571268

170. Sulaiman E, Kosaka T, Matsui N (2011) High power density design of 6-slot-8-pole hybrid excitation flux switching machine for hybrid electric vehicles. IEEE Trans Magn 47:4453-4456. https://doi.org/10.1109/TMAG.2011.2140315

171. Cajander D, Le-Huy H (2006) Design and optimization of a torque controller for a switched reluctance motor drive for electric vehicles by simulation. Math Comput Simul 71:333-344. https://doi.org/10.1016/j.matcom.2006.02.025

172. Gan C, Wu J, Hu Y et al (2017) New integrated multilevel converter for switched reluctance motor drives in plug-in hybrid electric vehicles with flexible energy conversion. IEEE Trans Power Electron 32:3754-3766. https://doi.org/10.1109/TPEL. 2016.2583467

173. Direnzo MT (2000) Switched reluctance motor control-basic operation and example using the TMS320F240. In: Appl Rep SPRA420A, pp 1-62

174. Rahman KM, Fahimi B, Suresh G et al (2000) Advantages of switched reluctance motor applications to EV and HEV: design and control issues. IEEE Trans Ind Appl 36:111-121. https:// doi.org/10.1109/28.821805

175. Hu Y, Gan C, Cao W et al (2015) Split converter-fed SRM drive for flexible charging in EV/HEV applications. IEEE Trans Ind Electron 62:6085-6095. https://doi.org/10.1109/TIE.2015. 2426142

176. Zhu ZQ, Howe D (2007) Electrical machines and drives for electric, hybrid, and fuel cell vehicles. Proc IEEE 95:746-765. https://doi.org/10.1109/JPROC.2006.892482
177. Zhang L, Member S, Fan Y et al (2017) Design and analysis of a new five-phase brushless for electric vehicles. IEEE Trans Ind Appl 53:3428-3437

178. Kommula BN (2015) Performance evaluation of hybrid fuzzy PI speed controller for brushless DC motor for electric vehicle application. In: 2015 Conference on power, control, communication and computational technologies for sustainable growth (PCCCTSG), pp 266-270

179. Ni Q, Li Q, Zhu X, Yi D, Shi K (2015) Energy management control strategy for plug-in hybrid electric vehicle with brushless dual- rotor flux-switching permanent magnet motor. In: 18th international conference on electrical machines and systems (ICEMS), pp 818-823

180. Ding S, Cheng M, Wang Z et al (2011) A hybrid energy source based double-stator permanent magnet brushless motor drive for hybrid electric vehicles. In: International conference on electrical machines and systems, pp 1-5

181. Wang Y, Zhang X, Yuan X, Liu G (2011) Position-sensorless hybrid sliding-mode control of electric vehicles with brushless DC motor. IEEE Trans Veh Technol 60:421-432. https://doi. org/10.1109/TVT.2010.2100415

182. Bianchi N, Dai Pre M (2003) Active power filter control using neural network technologies. IEE Proc-Electric Power Appl 150:139-145. https://doi.org/10.1049/ip-epa

183. Dadashnialehi A, Bab-Hadiashar A, Cao Z, Kapoor A (2015) Intelligent sensorless antilock braking system for brushless inwheel electric vehicles. IEEE Trans Ind Electron 62:1629-1638. https://doi.org/10.1109/TIE.2014.2341601

184. Bajec P, Member S, Pevec B et al (2005) Extending the lowspeed operation range of PM generator in automotive applications using novel AC-DC converter control. IEEE Trans Industr Electron 52(2):436-443. https://doi.org/10.1109/tie.2005. 84391252:436-443

185. Bajec P, Pevec B, Miljavec D (2010) Optimal control of brushless PM motor in parallel hybrid propulsion system. Mechatronics 20(4):64-473. https://doi.org/10.1016/j. mechatronics.2010.04.004

186. Yu L, Zhang Z, Chen Z, Yan Y (2014) Analysis and verification of the doubly salient brushless DC generator for automobile auxiliary power unit application. IEEE Trans Ind Electron 61:6655-6663. https://doi.org/10.1109/TIE.2014.2320224

187. Na W, Park T, Kim T, Kwak S (2011) Light fuel-cell hybrid electric vehicles based on predictive controllers. IEEE Trans Veh Technol 60:89-97. https://doi.org/10.1109/TVT.2010. 2087045

188. Shah NP, Hirzel AD, Cho B (2010) Transmissionless selectively aligned surface-permanent-magnet BLDC motor in hybrid electric vehicles. IEEE Trans Ind Electron 57:669-677. https:// doi.org/10.1109/TIE.2009.2036022

189. Milivojevic N, Krishnamurthy M, Gurkaynak Y et al (2012) Stability analysis of FPGA-based control of brushless DC motors and generators using digital PWM technique. IEEE Trans Ind Electron 59:343-351. https://doi.org/10.1109/TIE. 2011.2146220

190. Chen GH, Cheng MY (2007) Implementation of a highly reliable hybrid electric scooter drive. IEEE Trans Ind Electron 54:2462-2473. https://doi.org/10.1109/TIE.2007.900357

191. Zheng P, Liu Y, Wang Y, Cheng S (2005) Magnetization analysis of the brushless DC motor used for hybrid electric vehicle. 41:2003-2005

192. Bai J, Zheng P, Tong C et al (2015) Characteristic analysis and verification of the magnetic-field-modulated brushless doublerotor machine. IEEE Trans Ind Electron 62:4023-4033. https:// doi.org/10.1109/TIE.2014.2381159

193. Bostanci E, Neuschl Z, Plikat R (2015) Influence of phase magnetic couplings on phase current characteristics of 
multiphase BLDC machines with overlapping phase windings. IEEE Trans Magn. https://doi.org/10.1109/tmag.2015.2430833

194. Yan HS, Wu YC (2006) A novel configuration for a brushless DC motor with an integrated planetary gear train. J Magn Magn Mater 301:532-540. https://doi.org/10.1016/j.jmmm.2005.07. 031

195. Ashok RB, Kumar BM (2017) Comparative Analysis of BLDC motor for different control topology. Energy Procedia 117:314-320. https://doi.org/10.1016/j.egypro.2017.05.137

196. Salehi Arashloo R, Romeral Martinez JL, Salehifar M, MorenoEguilaz M (2014) Genetic algorithm-based output power optimisation of fault tolerant five-phase brushless direct current drives applicable for electrical and hybrid electrical vehicles. IET Electr Power Appl 8:267-277. https://doi.org/10.1049/ietepa.2013.0247

197. Salehifar M, Moreno-Eguilaz M, Putrus G, Barras P (2016) Simplified fault tolerant finite control set model predictive control of a five-phase inverter supplying BLDC motor in electric vehicle drive. Electr Power Syst Res 132:56-66. https:// doi.org/10.1016/j.epsr.2015.10.030

198. Naseri F, Farjah E, Ghanbari T (2017) An efficient regenerative braking system based on battery/supercapacitor for electric, hybrid, and plug-in hybrid electric vehicles with BLDC motor. IEEE Trans Veh Technol 66:3724-3738. https://doi.org/10. 1109/TVT.2016.2611655

199. Sharifan S, Ebrahimi S, Oraee A, Oraee H (2015) Performance comparison between brushless PM and induction motors for hybrid electric vehicle applications. In: 2015 Intl Aegean conference on electrical machines \& power electronics (ACEMP), 2015 Intl Conference on optimization of electrical \& electronic equipment (OPTIM) \& Intl symposium on advanced electromechanical motion systems (ELECTROMOTION), pp 719-724. https://doi.org/10.1109/optim.2015.7492473

200. Liu P, Liu HP (2012) Permanent-magnet synchronous motor drive system for electric vehicles using bidirectional Z-source inverter. IET Electr Syst Transp 2:178. https://doi.org/10.1049/ iet-est.2011.0036

201. Ping L, He-ping L (2011) Application of Z-source inverter for permanent-magnet synchronous motor drive system for electric vehicles. Procedia Eng 15:309-314. https://doi.org/10.1016/j. proeng.2011.08.060

202. Guo Q, Zhang C, Li L et al (2016) Design and implementation of a loss optimization control for electric vehicle in-wheel permanent-magnet synchronous motor direct drive system. Energy Procedia 105:2253-2259. https://doi.org/10.1016/j.egypro.2017. 03.644

203. Liu X, Zhang C, Li K, Zhang Q (2017) Robust current controlbased generalized predictive control with sliding mode disturbance compensation for PMSM drives. ISA Trans 71:542-552. https://doi.org/10.1016/j.isatra.2017.08.015

204. Drive I, Choudhury A, Pillay P (2016) Discontinuous hybridPWM-based DC-link voltage balancing algorithm for a threelevel neutral-point-clamped (NPC) traction inverter. IEEE Trans Ind Appl 52(4):3071-3082

205. Da Ru D, Morandin M, Bolognani S, Castiello M (2017) Test bench for emulating a variety of salient rotor electrical propulsion machines with a single permanent-magnet synchronous machine drive. IET Electr Syst Transp 7:55-64. https://doi.org/ 10.1049/iet-est.2016.0026

206. Carpiuc SC, Lazar C (2017) Modeling of synchronous electric machines for real-time simulation and automotive applications. J Franklin Inst 354:6258-6281. https://doi.org/10.1016/j. jfranklin.2017.07.030

207. Ke Z, Zhang J, Degner MW (2016) DC bus capacitor discharge of permanent magnet synchronous machine drive systems for hybrid electric vehicles. IEEE Trans Ind Appl 53:241-246. https://doi.org/10.1109/TIA.2016.2636279

208. Liu Y, Cheng D, Bai J et al (2012) Topology comparison of compound-structure permanent-magnet synchronous machines. IEEE Trans Ind Appl 48:2217-2222. https://doi.org/10.1109/ TIA.2012.2226856

209. Hafner M, Finken T, Felden M, Hameyer K (2011) Automated virtual prototyping of permanent magnet synchronous machines for HEVs. IEEE Trans Magn 47:1018-1021. https://doi.org/10. 1109/TMAG.2010.2091675

210. Zheng P, Zhao J, Liu R et al (2010) Magnetic characteristics investigation of an axial-axial flux compound-structure PMSM used for HEVs. IEEE Trans Magn 46:2191-2194. https://doi. org/10.1109/TMAG.2010.2042042

211. Kim KC, Lim SB, Koo DH, Lee J (2006) The shape design of permanent magnet for permanent magnet synchronous motor considering partial demagnetization. IEEE Trans Magn 42:3485-3487. https://doi.org/10.1109/TMAG.2006.879077

212. Henneberger S, Pahner U, Hameyer K, Belmans R (1997) Computation of a highly saturated permanent magnet synchronous motor for a hybrid electric vehicle. IEEE Trans Magn 33:4086-4088. https://doi.org/10.1109/20.619671

213. Adeoye AOM, Oladapo BI, Adekunle AA et al (2017) Design, simulation and implementation of a PID vector control for EHVPMSM for an automobile with hybrid technology. J Mater Res Technol. https://doi.org/10.1016/j.jmrt.2017.07.005

214. Ayaz M, Mese E (2016) A permanent magnet alternator with increased power capability for hybrid electric vehicle applications. Electr Power Syst Res 133:292-303. https://doi.org/10. 1016/j.epsr.2015.12.035

215. Liu J, Tong C, Jin Z et al (2017) Research on system control and energy management strategy of flux-modulated compoundstructure permanent magnet synchronous machine. CES Trans Electr Mach Syst 1:100-108

216. Morimoto S, Ooi S, Inoue Y, Sanada M (2014) Experimental evaluation of a rare-earth-free PMASynRM with ferrite magnets for automotive applications. IEEE Trans Ind Electron 61:5749-5756. https://doi.org/10.1109/TIE.2013.2289856

217. Zhang G, Hua W, Cheng M et al. (2014) Investigation of an improved hybrid-excitation flux switching brushless machine for HEV/EV applications. In: 2014 IEEE energy conversion congress and exposition (ECCE). IEEE, pp 5852-5857

218. Zhang J, Yao H, Rizzoni G (2017) Fault diagnosis for electric drive systems of electrified vehicles based on structural analysis. IEEE Trans Veh Technol 66:1027-1039. https://doi.org/10. 1109/TVT.2016.2556691

219. Alexandrou AD, Adamopoulos NK, Kladas AG (2016) Development of a constant switching frequency deadbeat predictive control technique for field-oriented synchronous permanentmagnet motor drive. IEEE Trans Ind Electron 63:5167-5175. https://doi.org/10.1109/TIE.2016.2559419

220. Akrad A, Hilairet M, Diallo D (2011) Design of a fault-tolerant controller based on observers for a PMSM drive. IEEE Trans Ind Electron 58:1416-1427. https://doi.org/10.1109/TIE.2010. 2050756

221. Xiang C, Liu F, Liu H et al (2016) Nonlinear dynamic behaviors of permanent magnet synchronous motors in electric vehicles caused by unbalanced BIT. J Sound Vib 371:277-294. https:// doi.org/10.1016/j.jsv.2016.02.015

222. Jarzebowicz L, Karwowski K, Kulesza WJ (2017) Sensorless algorithm for sustaining controllability of IPMSM drive in electric vehicle after resolver fault. Control Eng Pract 58:117-126. https://doi.org/10.1016/j.conengprac.2016.10. 00458:117-126

223. Estima JO, Marques Cardoso AJ (2012) Efficiency analysis of drive train topologies applied to electric/hybrid vehicles. IEEE 
Trans Veh Technol 61:1021-1031. https://doi.org/10.1109/TVT. 2012.2186993

224. Kamiev K, Montonen J, Ragavendra MP et al (2013) Design principles of permanent magnet synchronous machines for parallel hybrid or traction applications. IEEE Trans Ind Electron 60:4881-4890. https://doi.org/10.1109/TIE.2012.2221117

225. Omrane I, Etien E, Dib W, Bachelier O (2015) Modeling and simulation of soft sensor design for real-time speed and position estimation of PMSM. ISA Trans 57:329-339. https://doi.org/10. 1016/j.isatra.2014.06.004

226. Rabiei A, Thiringer T, Alatalo M, Grunditz E (2016) Improved maximum torque per ampere algorithm accounting for core saturation, cross coupling effect and temperature for a PM intended for vehicular applications. IEEE Trans Transp Electrif. https://doi.org/10.1109/tte.2016.2528505

227. Singh AK (2014) Analysis of induction motor for electric vehicle application based on drive cycle analysis. In: 2014 IEEE international conference on power electronics, drives and energy systems (PEDES) (2014), pp 1-6

228. Prakash R, Akhtar MJ, Behera RK, Parida SK (2014) Design of a three phase squirrel cage induction motor for electric propulsion system. IFAC Proc 47:801-806. https://doi.org/10.3182/ 20140313-3-IN-3024.00242

229. Mapelli FL, Tarsitano D, Cheli F (2017) MRAS rotor resistance estimators for EV vector controlled induction motor traction drive: analysis and experimental results. Electr Power Syst Res 146:298-307. https://doi.org/10.1016/j.epsr.2017.02.005

230. Seera M, Lim CP, Nahavandi S, Loo CK (2014) Condition monitoring of induction motors: a review and an application of an ensemble of hybrid intelligent models. Expert Syst Appl 41:4891-4903. https://doi.org/10.1016/j.eswa.2014.02.028

231. Cheng S, Li C, Chai F, Gong H (2012) Research on induction motor for mini electric vehicles. Energy Procedia 17:249-257. https://doi.org/10.1016/j.egypro.2012.02.091

232. Pal A, Kumar R, Das S (2016) Sensorless speed control of induction motor driven electric vehicle using model reference adaptive controller. Energy Procedia 90:540-551. https://doi. org/10.1016/j.egypro.2016.11.222

233. Trzynadlowski AM, Farasat M, Fadali MS (2014) Efficiency improved sensorless control scheme for electric vehicle induction motors. IET Electr Syst Transp 4:122-131. https://doi.org/ 10.1049/iet-est.2014.0018

234. Iffouzar K, Amrouche B, Otmane Cherif $\mathrm{T}$ et al (2017) Improved direct field oriented control of multiphase induction motor used in hybrid electric vehicle application. Int J Hydrogen Energy 42:19296-19308. https://doi.org/10.1016/j.ijhydene. 2017.06.195

235. Buyukdegirmenci VT, Bazzi AM, Krein PT (2014) Evaluation of induction and permanent-magnet synchronous machines using drive-cycle energy and loss minimization in traction applications. IEEE Trans Ind Appl 50:395-403. https://doi.org/ 10.1109/TIA.2013.2266352

236. Liu Y, Member S, Xu L (2013) The dual-current-loop controlled doubly fed induction motor for EV/HEV applications. IEEE Trans Energy Convers 28:1045-1052. https://doi.org/10.1109/ tec.2013.2279853

237. Choi S, Akin B, Kwak S, Toliyat H (2014) A compact error management algorithm to minimize false-alarm rate of motor/generator faults in (hybrid) electric vehicles. IEEE J Emerg Sel Top Power Electron 2:618-626. https://doi.org/10. 1109/JESTPE.2014.2302902

238. Khoucha F, Lagoun SM, Marouani K et al (2010) Hybrid cascaded $\mathrm{H}$-bridge multilevel-inverter induction-motor-drive direct torque control for automotive applications. IEEE Trans Ind Electron 57:892-899. https://doi.org/10.1109/TIE.2009.2037105
239. Adžíc EM, Adžíc MS, Katić VA et al (2013) Development of high-reliability EV and HEV IM propulsion drive with ultra-low latency HIL environment. IEEE Trans Ind Inform 9:630-639. https://doi.org/10.1109/TII.2012.2222649

240. Li W, Cao J, Zhang X (2010) Electrothermal analysis of induction motor with compound cage rotor used for PHEV. IEEE Trans Ind Electron 57:660-668. https://doi.org/10.1109/ TIE.2009.2033088

241. Yoshimoto K, Kawamura A, Hoshi N (1998) Traction control of anti-directional-twin-rotary motor drive based on electric vehicle driving simulator. In: PESC 98 Rec 29th annu IEEE power electron spec conf (Cat No98CH36196), vol 1, pp 578-582. https://doi.org/10.1109/pesc.1998.701956

242. Qianfan Z, Shukang C, Liwei S, Yulong P (2005) Axial excited hybrid reluctant motor applied in electric vehicles and research of its axial coil signal. IEEE Trans Magn 41:518-521. https:// doi.org/10.1109/TMAG.2004.839276

243. Talebi S, Nikbakhtian B, Toliyat HA (2007) A novel algorithm for designing the PID controllers of high-speed flywheels for traction applications. In: Veh power propuls conf 2007 VPPC 2007 IEEE, pp 574-579. https://doi.org/10.1109/vppc.2007. 4544188

244. Khan M, Member S, Kar NC, Member S (2008) Speed tracking performance of fuzzy based vector control of induction motor drives for hybrid electric vehicles. In: Canadian conference on electrical and computer engineering, pp 607-610. https://doi. org/10.1109/ccece.2008.4564606

245. Salvatore N, Cascella GL, Aquila AD et al. (2008) Stator flux oriented control of induction motors using variable-saturation regulators. In: International symposium on power electronics, electrical drives, automation and motion, pp 96-100. https://doi. org/10.1109/speedham.2008.4581106

246. Bouchafaa F, Beriber D, Boucherit MS, Berkouk EM (2009) Enslavement and control of the multi DC-Bus link voltages using adaptive fuzzy. In: 2009 8th int symp adv electromechanical motion syst electr drives jt symp ELECTROMOTION 2009, pp 1-3. https://doi.org/10.1109/electromotion.2009. 5259075

247. Kim SH, Seok JK (2013) Maximum voltage utilization of IPMSMs using modulating voltage scalability for automotive applications. IEEE Trans Power Electron 28:5639-5646. https:// doi.org/10.1109/TPEL.2013.2253802

248. Seo H, Lee H, Lim W et al. (2014) Engine clutch pressure command control for a parallel hybrid vehicle at launching when traction motor failed. In: 2013 world electr veh symp exhib EVS 2014, pp 1-5. https://doi.org/10.1109/evs.2013.6914881

249. Rind S, Ren Y, Jiang L (2014) Traction motors and speed estimation techniques for sensorless control of electric vehicles: a review. In: 2014 49th int univ power eng conf, pp 1-6. https:// doi.org/10.1109/upec.2014.6934646

250. Moghbeli H (2015) Transient and steady states analysis of traction motor drive with regenerative braking and using modified direct torque control (SVM-DTC). In: The 6th power electronics, drive systems \& technologies conference (PEDSTC2015), pp 3-4. https://doi.org/10.1109/pedstc.2015. 7093345

251. Abe T, Oba R, Maeda K, Higuchi T (2015) Influence of rotor structure on the torque characteristic of a novel claw pole type half-wave rectified variable field flux motor keywords structure and torque equation of proposed novel CP-HVFM motor structure. In: 2015 17th Eur conf power electron appl (EPE'15 ECCE-Europe), pp 1-9. https://doi.org/10.1109/epe.2015. 7309284

252. Lashkevich M, Anuchin A, Aliamkin D, Briz F (2017) Investigation of self-sensing rotor position estimation methods for synchronous homopolar motor in traction applications. In: Proc 
IECON 2017-43rd annu conf IEEE ind electron soc 2017Janua, pp 8225-8229. https://doi.org/10.1109/iecon.2017. 8217443

253. Do HD, Anuchin A, Shpak D, Zharkov A (2018) Overvoltage protection for interior permanent magnet synchronous motor testbench. In: 2018 25th International Workshop on Electric Drives: Optimization in Control of Electric Drives (IWED), Moscow, pp 1-4. https://doi.org/10.1109/iwed.2018.8321396

254. Idrissi Z El, Fadil H El, Giri F (2018) Nonlinear control of salient-pole PMSM for electric vehicles traction. In: 2018 19th IEEE mediterr electrotech conf, pp 231-236. https://doi.org/10. 1109/melcon.2018.8379099

255. Zhang C, Lin Z, Liu J et al (2018) Consensus-based totalamount cooperative tracking control for multi-motor locomotive traction system. J Franklin Inst 000:1-16. https://doi.org/10. 1016/j.jfranklin.2017.11.025

256. Savitski D, Schleinin D, Ivanov V et al (2017) Improvement of traction performance and off-road mobility for a vehicle with four individual electric motors: driving over icy road. J Terramechanics 69:33-43. https://doi.org/10.1016/j.jterra.2016.10. 005

257. Trovão JP, Silva MA, Antunes CH, Dubois MR (2017) Stability enhancement of the motor drive DC input voltage of an electric vehicle using on-board hybrid energy storage systems. Appl Energy 205:244-259. https://doi.org/10.1016/j.apenergy.2017. 07.084

258. Becherif M, Ramadan HS, Ayad MY et al (2017) Efficient startup energy management via nonlinear control for eco-traction systems. Appl Energy 187:899-909. https://doi.org/10.1016/j. apenergy.2016.11.007

259. Ding X, Guo H, Xiong R et al (2017) A new strategy of efficiency enhancement for traction systems in electric vehicles. Appl Energy 205:880-891. https://doi.org/10.1016/j.apenergy. 2017.08.051

260. Mapelli FL, Tarsitano D, Cheli F (2014) A rotor resistance MRAS estimator for EV induction motor traction drive based on torque and reactive stator power: Simulation and experimental results. In: 2014 international conference on electrical machines (ICEM), pp 31-37. https://doi.org/10.1109/icelmach.2014. 6960155

261. Niu G, Liu S (2018) Demagnetization monitoring and life extending control for permanent magnet-driven traction systems. Mech Syst Signal Process 103:264-279. https://doi.org/10. 1016/j.ymssp.2017.10.003

262. Kuntanapreeda S (2015) Super-twisting sliding-mode traction control of vehicles with tractive force observer. Control Eng Pract 38:26-36. https://doi.org/10.1016/j.conengprac.2015.01. 004

263. Jalali M, Khajepour A, Chen SK, Litkouhi B (2016) Integrated stability and traction control for electric vehicles using model predictive control. Control Eng Pract 54:256-266. https://doi. org/10.1016/j.conengprac.2016.06.005

264. Kim J, Lee J (2018) Traction-energy balancing adaptive control with slip optimization for wheeled robots on rough terrain. Cogn Syst Res 49:142-156. https://doi.org/10.1016/j.cogsys.2018.01. 007

265. Wolfs P, Quan L (2006) A current-sensor-free incremental conductance single cell MPPT for high performance vehicle solar arrays. In: PESC Rec-IEEE annu power electron spec conf. https://doi.org/10.1109/pesc.2006.1711749

266. Wolfs P, Li Q (2007) Hardware implementation and performance analysis of a current-sensor-free single cell MPPT for high performance vehicle solar arrays. PESC Rec-IEEE annu power electron spec conf, pp 132-137. https://doi.org/10.1109/ pesc. 2007.4341976
267. Zhang X, Chau KT, Yu C, Chan CC (2008) An optimal solarthermoelectric hybrid energy system for hybrid electric vehicles. In: 2008 IEEE vehicle power and propulsion conference, VPPC 2008. IEEE, pp 1-6

268. Gurkaynak Y, Li Z, Khaligh A (2009) A novel grid-tied, solar powered residential home with plug-in hybrid electric vehicle (PHEV) loads BT-5th IEEE vehicle power and propulsion conference, VPPC'09, September 7, 2009-September 10, 2009.pp 813-816. https://doi.org/10.1109/vppc.2009.5289765

269. Ocran TA, Cao J, Cao B, Sun X (2005) Artificial neural network maximum power point tracker for solar electric vehicle. Tsinghua Sci Technol 10:204-208. https://doi.org/10.1016/S10070214(05)70055-9

270. Khoucha F, Benrabah A, Herizi O et al. (2013) An improved MPPT interleaved boost converter for solar electric vehicle application. In: 4th International conference on power engineering, energy and electrical drives, pp 1076-1081. https://doi. org/10.1109/powereng.2013.663576013-17

271. Shuang DU (2013) Algorithm research on maximum power point tracking of solar electric vehicle. In: Proceedings 2013 international conference on mechatronic sciences, electric engineering and computer (MEC), pp 74-78.https://doi.org/10. $1109 / \mathrm{mec} .2013 .6885052$

272. Hadagali N et al (2014) Bidirectional dc/dc converter system for solar and fuel cell. In: 2014 annual international conference on emerging research areas: magnetics, machines and drives (AICERA/iCMMD), pp 1-6

273. Armstrong PM, Wong R, Kang R et al. (2013) A reconfigurable PV array scheme integrated into an electric vehicle. In: IET hybrid and electric vehicles conference 2013 (HEVC 2013), London, 2013, pp 1-7.https://doi.org/10.1049/cp.2013.1910

274. Sakib KN, Member S, Kabir MZ, Williamson SS (2013) Cadmium telluride solar cell: from device modeling to electric vehicle battery management. In: 2013 IEEE transportation electrification conference and expo (ITEC), pp 1-8.https://doi. org/10.1109/itec.2013.6574490

275. Jeddi N, El Amraoui L, Rico FT (2017) A comparative study and analysis of different models for photovoltaic (PV) array using in solar car. In: 2017 Twelfth international conference on ecological vehicles and renewable energies (EVER). IEEE, pp $1-10$

276. Wolfs P, Quan Li (2006) A current-sensor-free incremental conductance single cell MPPT for high performance vehicle solar arrays. In: 37th IEEE power electronics specialists conference. IEEE, pp 1-7

277. Ahadi A, Liang X (2017) A stand-alone hybrid renewable energy system assessment using cost optimization method. In: 2017 IEEE international conference on industrial technology (ICIT). IEEE, pp 376-381

278. Zhang X, Chau KT, Yu C, Chan CC (2008) An optimal solarthermoelectric hybrid energy system for hybrid electric vehicles. In: 2008 IEEE veh power propuls conf VPPC 2008. https://doi. org/10.1109/vppc.2008.4677488

279. Kalla UK, Gurjar D, Rathore KS, Dixit P (2016) An efficient controller for PV operated PMBLDC drive based electric vehicle system. In: 2016 IEEE 7th power India international conference (PIICON). IEEE, pp 1-6

280. El-Saady G, Sharaf AM, Makky AM et al. An error driven hybrid neuro-fuzzy torque/speed controller for electrical vehicle induction motor drive. In: Proceedings of the intelligent vehicles'94 symposium. IEEE, pp 449-454

281. Schuss C., Eichberger B., Rahkonen T. (2012) A monitoring system for the use of solar energy in electric and hybrid electric vehicles. In: 2012 IEEE I2MTC - int instrum meas technol conf proc, pp 524-527. https://doi.org/10.1109/i2mtc.2012.6229214 
282. Nakir I, Durusu A, Ugur E, Tanrioven M (2012) Performance assessment of MPPT algorithms for vehicle integrated solar systems. IEEE Int Energy Conf Exhib ENERGYCON 2012: 1034-1038. https://doi.org/10.1109/EnergyCon.2012.6347721

283. Sarigiannidis AG, Kakosimos PE, Kladas AG (2014) Solar energy exploitation enhancing driving autonomy of electric vehicles. MedPower, pp 1-5. https://doi.org/10.1049/cp.2014. 1649

284. Forrisi I, Martin J, Nahid-mobarakeh B et al. (2016) A new approach for DC bus voltage balancing in a solar electric vehicle charging station. In: IEEE transportation electrification conference and expo (ITEC), pp 1-5. https://doi.org/10.1109/itec. 2016.7520240

285. Kishore P, Ananth M, Chidambaram S et al. (2013) Solar based hybrid electric powered wheel chair, pp 18-24. https://doi.org/ 10.1109/tiiec.2013.11

286. Logeswaran T, Senthilkumar A (2014) A review of maximum power point tracking algorithms for photovoltaic systems under uniform and non-uniform irradiances. Energy Procedia 54:228-235. https://doi.org/10.1016/j.egypro.2014.07.266

287. ElMenshawy M, ElMenshawy M, Massoud A, Gastli A (2016) Solar car efficient power converters' design. In: 2016 IEEE symposium on computer applications \& industrial electronics (ISCAIE). IEEE, pp 177-182

288. Bhattacharya S (2016) Coordinated decentralized control for PV-EV based grid connected microgrids. In: 2016 IEEE 6th international conference on power systems (ICPS), New Delhi, 2016, pp 1-6.https://doi.org/10.1109/icpes.2016.7584213

289. Advantages and disadvantages of hybrid cars-conserve energy future. https://www.conserve-energy-future.com/advantagesand-disadvantages-of-hybrid-cars.php. Accessed 5 Oct 2018

290. Bagloee SA, Tavana M, Asadi M, Oliver T (2016) Autonomous vehicles: challenges, opportunities, and future implications for transportation policies. J Mod Transp 24:284-303. https://doi. org/10.1007/s40534-016-0117-3

291. Frost and Sullivan (2018) Global electric vehicle market outlook, 2018. https://store.frost.com/global-electric-vehiclemarket-outlook-2018.html. Accessed 5 Oct 2018

292. Iyer B, Mangaleswaran R et al (2017) The future of mobility in India: challenges \& opportunities for the auto component industry. https://www.mckinsey.com/ /media/mckinsey/ industries/automotive\%20and\%20assembly/our\%20insights/ the $\% 20$ future $\% 20 \mathrm{of} \% 20$ mobility $\% 20 \mathrm{in} \% 20 \mathrm{india} /$ the-futureof-mobility-in-india.ashx. Accessed 5 Oct 2018

293. Stanley M, International C, Alsford J et al. (2017) Sustainability compendium: MS views on sustainability topics morgan stanley' s sustainability research team. 1-62

294. IEA (2009) Hybrid and Electric Vehicles, the electric drive establishes a market foothold. http://www.ieahev.org/assets/1/7/ 2008_annual_report.pdf. Accessed 5 Oct 2018

295. Frost \& Sullivan (2007) Global market analysis of plug in hybrid Electric Vehicles. http://www.emic-bg.org/files/Global_Market_ Analysis_of_Plug_in_Hybrid_Electric.pdf. Accessed 5 Oct 2018

296. Singh S (2018) Global electric vehicle market looks to power up in 2018. In: Forbes. https://www.forbes.com/sites/sarwantsingh/ 2018/04/03/global-electric-vehicle-market-looks-to-fire-on-allmotors-in-2018/\#6bf966142927. Accessed 5 Oct 2018

297. Electric Cars to Reach Price Parity by 2025 I Bloomberg NEF. https://about.bnef.com/blog/electric-cars-reach-price-parity2025/. Accessed 6 Oct 2018

298. Electric Cars vs Gas Cars: What Do They Cost?| EnergySage. https://www.energysage.com/electric-vehicles/costs-andbenefits-evs/evs-vs-fossil-fuel-vehicles/. Accessed 5 Oct 2018

299. Electric cars "will be cheaper than conventional vehicles by 2022"| Environmentl The Guardian. https://www.theguardian. com/environment/2016/feb/25/electric-cars-will-be-cheaperthan-conventional-vehicles-by-2022. Accessed 5 Oct 2018

300. Propfe B, Redelbach M, Santini DJ et al. (2012) Cost analysis of plug-in hybrid electric vehicles including maintenance \& repair costs and resale values implementing agreement on hybrid and electric vehicles. 5:6862. https://doi.org/10.3390/wevj5040886

301. Panday A, Bansal HO (2016) Energy management strategy for hybrid electric vehicles using genetic algorithm. J Renew Sustain Energy 8:015701. https://doi.org/10.1063/1.4938552

302. Efficiency Compared: Battery-Electric 73\%, Hydrogen 22\%, ICE $13 \%$. https://insideevs.com/efficiency-compared-batteryelectric-73-hydrogen-22-ice-13/. Accessed 5 Oct 2018

303. Wang M, Zhu L, Le AV et al (2017) A multifunctional battery module design for electric vehicle. J Mod Transp 25:218-222. https://doi.org/10.1007/s40534-017-0144-8

304. Panday A, Bansal HO (2014) Green transportation: need, technology and challenges. Int J Glob Energy Issues 37:304. https:// doi.org/10.1504/IJGEI.2014.067663 